\title{
Comparative transcriptome analysis reveals different strategies for degradation of steam-exploded sugarcane bagasse by Aspergillus niger and Trichoderma reesei
}

Gustavo Pagotto Borin ${ }^{1}$, Camila Cristina Sanchez ${ }^{1}$, Eliane Silva de Santana ${ }^{1}$, Guilherme Keppe Zanini', Renato Augusto Corrêa dos Santos ${ }^{1}$, Angélica de Oliveira Pontes ${ }^{1}$, Aline Tieppo de Souza ${ }^{1}$, Roberta Maria Menegaldo Tavares Soares Dal'Mas', Diego Mauricio Riaño-Pachónn 1,3, Gustavo Henrique Goldman ${ }^{2}$ and Juliana Velasco de Castro Oliveira ${ }^{1 *}$

\begin{abstract}
Background: Second generation $(2 \mathrm{G})$ ethanol is produced by breaking down lignocellulosic biomass into fermentable sugars. In Brazil, sugarcane bagasse has been proposed as the lignocellulosic residue for this biofuel production. The enzymatic cocktails for the degradation of biomass-derived polysaccharides are mostly produced by fungi, such as Aspergillus niger and Trichoderma reesei. However, it is not yet fully understood how these microorganisms degrade plant biomass. In order to identify transcriptomic changes during steam-exploded bagasse (SEB) breakdown, we conducted a RNA-seq comparative transcriptome profiling of both fungi growing on SEB as carbon source.

Results: Particular attention was focused on CAZymes, sugar transporters, transcription factors (TFs) and other proteins related to lignocellulose degradation. Although genes coding for the main enzymes involved in biomass deconstruction were expressed by both fungal strains since the beginning of the growth in SEB, significant differences were found in their expression profiles. The expression of these enzymes is mainly regulated at the transcription level, and A. niger and T. reesei also showed differences in TFs content and in their expression. Several sugar transporters that were induced in both fungal strains could be new players on biomass degradation besides their role in sugar uptake. Interestingly, our findings revealed that in both strains several genes that code for proteins of unknown function and pro-oxidant, antioxidant, and detoxification enzymes were induced during growth in SEB as carbon source, but their specific roles on lignocellulose degradation remain to be elucidated.

Conclusions: This is the first report of a time-course experiment monitoring the degradation of pretreated bagasse by two important fungi using the RNA-seq technology. It was possible to identify a set of genes that might be applied in several biotechnology fields. The data suggest that these two microorganisms employ different strategies for biomass breakdown. This knowledge can be exploited for the rational design of enzymatic cocktails and $2 \mathrm{G}$ ethanol production improvement.
\end{abstract}

Keywords: Sugarcane bagasse, RNA-seq, Aspergillus niger, Trichoderma reesei, CAZymes, Transporters, Transcription factors

\footnotetext{
* Correspondence: juliana.velasco@bioetanol.org.br

${ }^{1}$ Laboratório Nacional de Ciência e Tecnologia do Bioetanol (CTBE), Centro Nacional de Pesquisa em Energia e Materiais (CNPEM), Av Giuseppe Maximo Scolfaro 10000, Campinas, São Paulo Caixa Postal 6170, 13083-970, Brazil Full list of author information is available at the end of the article
} 


\section{Background}

The global demand for renewable energy has led to the search and development of new technologies for biofuel production. Biofuels are produced from plants or agricultural, industrial and domestic wastes, and their use can help to reduce the world's dependence on oil and gasoline, being a viable alternative to fossil fuels. The main types of first generation biofuels commercially used are biodiesel, biogas and bioethanol, being the latter the most widely used in the world [1]. According to the U.S. Department of Energy, 24,570 millions of gallons of ethanol were produced in 2014, and the world's top producers were the United States and Brazil, accounting together for more than $80 \%$ of the global production (http://www.afdc.energy.gov). Although in the last 10 years Brazil has lost its leadership in ethanol production, it still has best economic model of ethanol industry due to its technology and vast amount of land available to sugarcane cultivation, a cheap feedstock [2, 3]. The Brazilian fermentation process is characterized by the use of very large tanks ( 0.5 to 3 million liters) and high yeast cell densities $(10-15 \% \mathrm{w} / \mathrm{v})$. The fermentations are carried out for a short period of 6-12 hours, reaching high alcohol concentration $(7-11 \% \mathrm{v} / \mathrm{v})$. At the end of the fermentation, yeast cells are harvested by centrifuging and reutilized in a next fermentation cycle, a quite peculiar trait in the Brazilian process [4].

Under these conditions, $270-280 \mathrm{~kg}$ of bagasse per ton of crushed sugarcane are generated as byproduct [2]. Currently, most of that bagasse is burned to generate biosteam and bioelectricity, which is in turn consumed by the distillery or refinery. However, bagasse could be used to produce second generation (2G) ethanol (or cellulosic ethanol). For this purpose, the plant biomass should be hydrolyzed to release fermentable sugars from the plant cell wall. Bagasse is composed of cellulose (38\%), hemicellulose (23\%), lignin (25\%) and a small percentage of other compounds [5]. Currently, a hectare of sugarcane can produce about 6,000 L of ethanol, and if $50 \%$ of the bagasse generated by the distilleries was used for $2 \mathrm{G}$ production, it would be possible to increase this volume to $10,000 \mathrm{~L} / \mathrm{ha}$ [6].

$2 \mathrm{G}$ ethanol technology includes three stages: $(i)$ a physical and/or chemical pretreatment of the plant biomass, that aims to decrease its recalcitrance, improving enzyme accessibility to cellulose and recovering monosaccharides from hemicelluloses, e.g., xylose; (ii) saccharification, the breakdown of complex polysaccharides (mainly cellulose, but also xylose-based polysaccharides) into monosaccharides, and (iii) fermentation, the bioethanol production from the released monosaccharides in $(i)$ and (ii). Although several improvements have been obtained in all these steps, the lack of yeasts capable of efficiently fermenting xylose and the high cost of the necessary enzymes in step (ii), represent bottlenecks to the $2 \mathrm{G}$ ethanol economic viability $[7,8]$.

Estimates of the costs of the enzymatic cocktails required for the saccharification process differ significantly, from $\$ 0.10 /$ gal to $\$ 0.40 /$ gal of ethanol [9]. Among other factors, these values depend on the type of biomass to be hydrolyzed, the pretreatment used, and the microorganisms that produce plant cell wall degrading enzymes (PCWDEs). In nature, the breakdown of lignocellulosic biomass is driven by a large community of microorganisms, with special highlight to the saprophytic fungi, such as Trichoderma reesei and Aspergillus niger, whose hydrolytic and oxidative enzymatic arsenal have been widely employed in these commercial enzymatic cocktails $[10,11]$. The lineages leading to $T$. reesei (Sordariomycetes) and $A$. niger (Eurotiomycetes) diverged more than 310 million years ago [12], so they have been exploring for a long time different strategies to extract carbon sources required for their growth from available biomass.

T. reesei was isolated from the Solomon Islands during the Second World War, colonizing tents and parachutes from the U.S. army [13]. It was found that the new organism (originally named $T$. viridae) was a good producer of cellulases and, as the interest in renewable energy sources was increasing, it became the subject of several studies related to polysaccharide degradation. In this sense, the development of a derived strain through a series of induced mutagenesis experiments resulted in the hypercellulolytic RUT-C30 that is catabolite-derepressed [14, 15]. Furthermore, due to its great ability to produce and secrete large amounts of cellulases and hemicellulases, $T$. reesei is considered a model for cellulose degradation $[16,17]$.

$A$. niger is the most important industrial fungus in the genus Aspergillus, being used to produce a wide range of commercial compounds [18]. The most important is citric acid, the main acidulant used in food and beverage industries. In addition to its importance in pharmaceutical and cosmetics industries, $A$. niger has been explored to produce organic acids such as gluconic and fumaric acids $[19,20]$. In relation to enzymes, $A$. niger is employed to produce pectinases, amylases and proteases, which are used in a variety of industrial processes, including juice clarification and detergent formulations [21-23]. Regarding the $2 \mathrm{G}$ ethanol industry, $A$. niger is used as source of enzymes for biomass degradation and host for heterologous protein production [24, 25].

The enzymes necessary for the breakdown of polysaccharides are usually subject to carbon catabolite repression (CCR), which means that growth on glucose or other preferred carbon sources represses their synthesis [26]. This process is regulated at the transcriptional level, and one of the major CCR players is the transcription factor CreA. In T. reesei RUT-C30, its orthologue Cre1, is truncated [14], allowing a higher enzyme 
production by this strain. Antagonistically, the crucial player in the induction of cellulases and hemicellulases is the transcription factor $\mathrm{XlnR}$, and its orthologue in $T$. reesei Xyr1. In addition, other proteins are involved in the positive (Ace2, Ace3, Hap2/3/5, Lae1, GalX, ManR, AraR) and negative (Ace1, Cre2) regulation of gene expression of those enzymes [27-29]. However, a complete understanding of transcriptional regulation and production of PCWDEs is still lacking and needs to be better investigated.

The activation and repression of these regulators depend on the inducers present in the environment or culture media, such as cellobiose, xylobiose, xylose, lactose, and sophorose, each of them being speciesdependent [28] and responsible to trigger the production of the enzymes that degrade biomass. These enzymes (and other proteins involved in the assembly of complex carbohydrates) are collectively identified as CarbohydrateActive enZymes (CAZymes) [30]. They are classified in classes and families, according to their sequence, structure and molecular mechanisms, by the online database CAZy (http://www.cazy.org). Enzyme classes covered by CAZy include glycoside hydrolase $(\mathrm{GH})$, carbohydrate esterase (CE), polysaccharide lyase (PL), glycosyltransferases (GT), and enzymes with auxiliary activity (AA). All of these classes contain enzymes that act on the biomass deconstruction, with the exception of GT and CE family 10.

Thus, gaining detailed knowledge about the molecular mechanisms behind biomass degradation and enzyme production can enable a fine genetic manipulation of these strains in order to increase their hydrolytic potential or the discovery of new enzymes or proteins, and their combinations that can improve the saccharification process. Although several studies have been done on $A$. niger and $T$. reesei to understand their transcriptional responses when grown on lignocellulosic biomass, we have studied for the first time, their time-dependent transcriptional response when grown on pretreated bagasse, one of the largest and most inexpensive lignocellulosic ethanol feedstocks.

\section{Results and discussion}

Simple sugars do not induce the full enzymatic repertoire that is encoded by a fungal genome. Moreover, the enzymatic arsenal produced in response to a specific plant biomass is likely to vary towards different substrates. Understanding the molecular mechanisms, particularly transcriptional control, in fungi that have evolved to degrade vegetal biomass will provide clues to improve the biomass saccharification step, thus being of paramount importance for the economic viability of $2 \mathrm{G}$ biofuel production.

There are few studies analyzing the transcriptome of A. niger grown in plant biomass (Table 1). Pullan et al.
[31] and Delmas et al. [32] described a comparative transcriptional study of this fungus grown on willow and wheat straw, respectively. Van Muster et al. [33] investigated the induction of CAZymes in wheat straw and in a carbon starvation condition. De Souza et al. [34] analyzed the transcriptome of $A$. niger grown in sugarcane bagasse, using a microarray platform. Besides these works, there are some studies using monomeric sugars as carbon sources [35-37], under starvation [38] or using mutant strains [39]. In T. reesei, two studies described its global gene expression profile growing on wheat straw [40] and wheat straw in comparison to lactose [41]. Dos Santos Castro et al. [42] compared the transcriptome of $T$. reesei during growth in cellulose, sophorose, and glucose; Hakkinen et al. [43] investigated the $T$. reesei transcriptome in several substrates, including sugarcane bagasse, using a microarray platform (Table 1). Two publications compared the secretome of both fungi, using proteomics, growing on complex substrates [44, 45]. In this work we studied, for the first time, to the best of our knowledge, the transcriptional response of both fungi when grown on pretreated lignocellulosic biomass.

We chose to compare the $T$. reesei RUT-C30 and $A$. niger N402 strains. As mentioned before, RUT-C30 is an industrial strain, which has important mutations that affect its lignocellulolytic phenotype. We were interested on A. niger $\mathrm{N} 402$ as in a previous work from our group [44], this strain showed a higher secretion of CAZymes than RUT-C30. Therefore, we wanted to gain more insights about the differences at the transcriptional level between both strains, and to identify potential new genes involved in the lignocellulose breakdown. A. niger and $T$. reesei were grown on steam-exploded sugarcane bagasse (SEB) as sole carbon source and biological duplicates were collected at 6,12 and $24 \mathrm{~h}$. Both fungi were also grown on fructose for $24 \mathrm{~h}$ as control condition in order to identify differentially expressed genes (DEG), responding to the lignocellulosic substrate. Poly-adenylated transcripts were sequenced in a HiSeq2000 system, and the resulting short reads were mapped to the respective reference genomes, achieving mapping rates of over $93 \%$ for both strains (Additional file 1). Analysis of exon-exon junctions revealed that saturation was achieved, i.e., increasing the number of sequenced reads would not have resulted in significantly more exon-exon junctions detected (data not shown). The average Pearson correlation coefficient between duplicated samples was 0.94.

We detected 7,359 genes in A. niger and 2,945 in T. reesei that are induced or repressed when SEB was used as the unique carbon source (genes with at least two-fold change) (Fig. 1 and Additional file 2). A. niger had 2.5 times more DEGs than $T$. reesei, despite both genomes being of approximately the same size (33.9 Mbp vs 32.7 


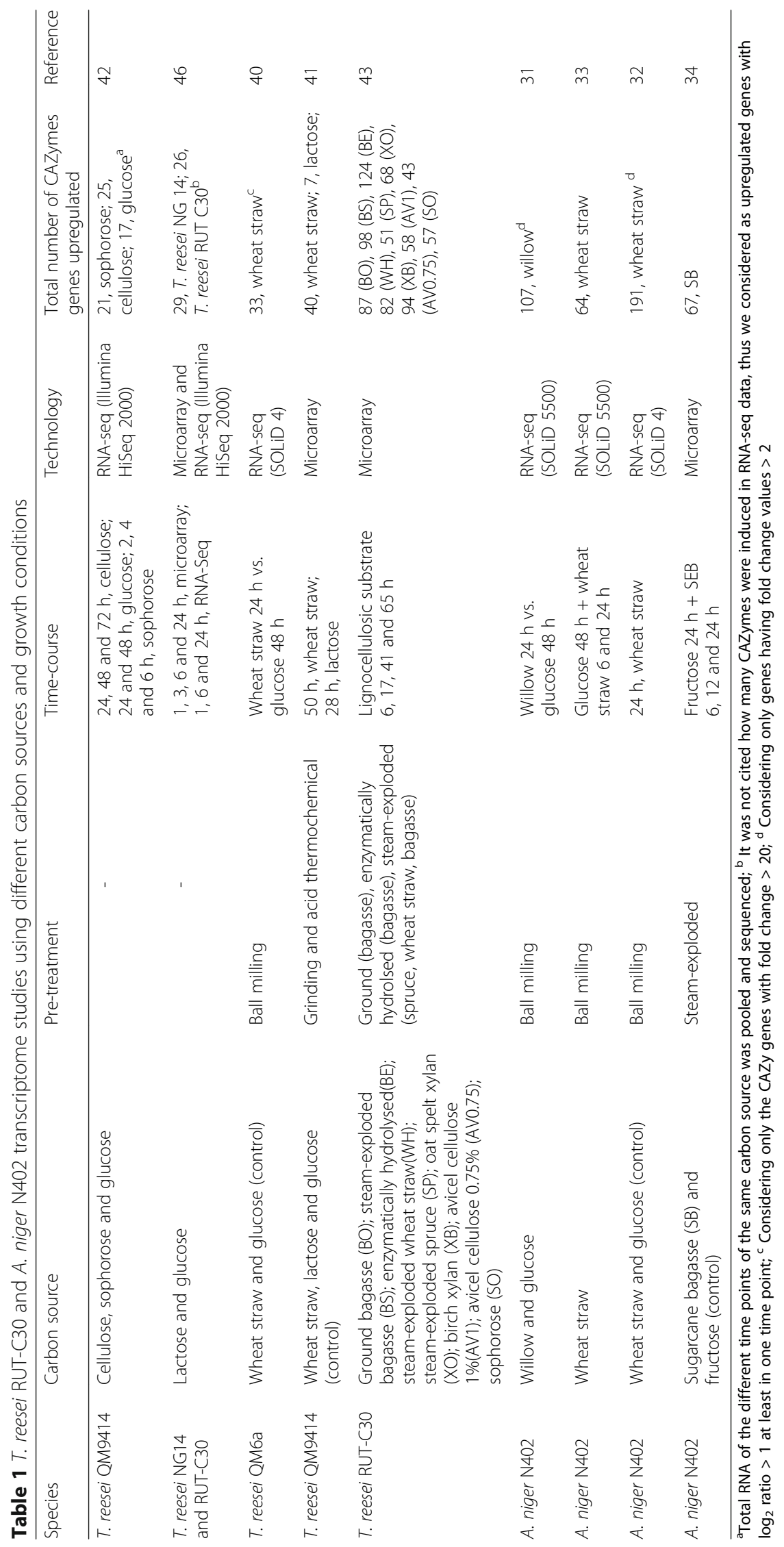




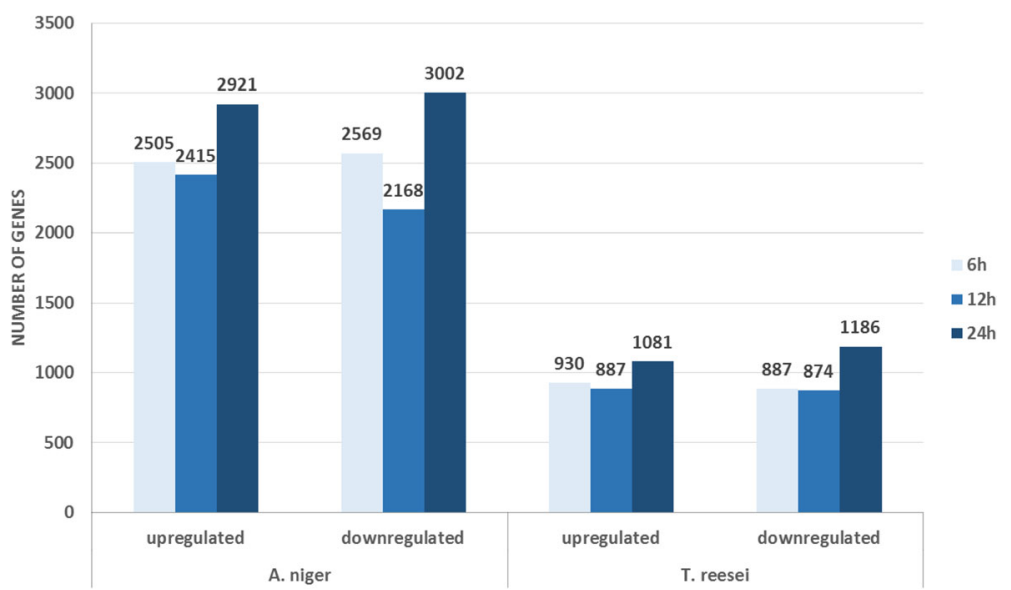

Fig. 1 Number of genes up and downregulated in A. niger N402 and T. reesei RUT-C30 grown on SEB for 6, 12 e 24 hours (h). The full list of DEGs is shown in Additional file 2

Mbp), and $A$. niger only having 1.4 times more predicted protein-coding genes than $T$. reesei $(14,165$ vs 9,852$)$. Thus, gene content alone cannot explain the difference in the number of DEGs between the two strains, but instead it should be a consequence of the individual ability of each fungus to respond to the recalcitrant biomass and to activate different pathways and genes for its degradation. It is worth noting that during the time course, time point $24 \mathrm{~h}$ showed a slightly larger number of DEGs in both fungi, probably due to the higher quantities of small molecules released after biomass cell wall degradation that could act as inducers.

Gene Ontology (GO) enrichment analysis for the gene set induced at time point $24 \mathrm{~h}$ (Fig. 2, Additional file 3) showed that both A. niger (Fig. 2a) and T. reesei (Fig. 2b) had in common the terms Carbohydrate metabolic process (GO: 0005975) and Carbohydrate transport (GO: 0008643); in addition, three categories associated with gene expression processes were enriched in $A$. niger, such as ribonucleoprotein complex biogenesis (GO: 0022613), ribosome biogenesis (GO: 0042254) and ncRNA processing (GO: 0034470) (Fig. 2a). Regarding the repressed genes, $A$. niger had enriched categories associated with nitrogen metabolism, such as nitrogen compound transport (GO: 0071705) and amino acid transport (GO: 0006865) (Fig. 2a). In the set of repressed genes in T. reesei, no GO categories were over represented.

The two GO terms commonly enriched for both fungi in the set of induced genes in SEB at 24 h (GO: 0005975 and GO: 0008643) include genes coding for CAZymes and transporters. This leads us to speculate that $T$. reesei and $A$. niger were spending their energy to the transcription and production of cellulolytic compounds, which were probably being secreted for biomass degradation and the release of small sugars, as shown by Borin et al. [44]. The released mono and disaccharides may serve as inducers of CAZyme-coding gene expression and activators of membrane transporters, whose function is to allow the transport of sugars from the extracellular to the intracellular microenvironment and also have a role in the induction of cellulase and hemicellulose biosynthesis $[46,47]$. For this reason, the protein synthesis machinery of the fungi should be activated to carry out protein translation of the induced genes, which explain the GO terms enriched in the set of $A$. niger induced genes in SEB at $24 \mathrm{~h}$

As our main interest is to understand how these fungal strains rearrange their transcriptional programs in response to the availability of a complex lignocellulosic substrate, we focused the following analyses on CAZymes, transporters, transcription factors, and other genes of interest. Genes coding proteins of unknown function were also of particular interest as they can represent new targets for further analysis.

\section{CAZymes}

CAZymes are Carbohydrate-Active Enzymes classified by the CAZy database. We focused on these enzymes, excluding the classe of glycosyl transferase and the carbohydrate esterase family 10 , as they are not related to carbohydrate degradation. We found that 190 CAZymes, in 62 different families, were upregulated in $A$. niger, while 105 CAZymes were upregulated in T. reesei, from 51 families (Fig. 3a and 3b, and Additional file 4 and 5). The genomes from both species have approximately the same proportion of CAZymes related to the total number of predicted genes, approx. 2.5\% for each species. However, $A$. niger is expressing a larger proportion of CAZymes than $T$. reesei $(1.3 \%$ vs $0.8 \%$, respectively), also from a larger number of different families (Fig. 3). The CAZyme transcriptional response in $A$. niger is more diverse than T. reesei, when SEB is the source of carbon. 

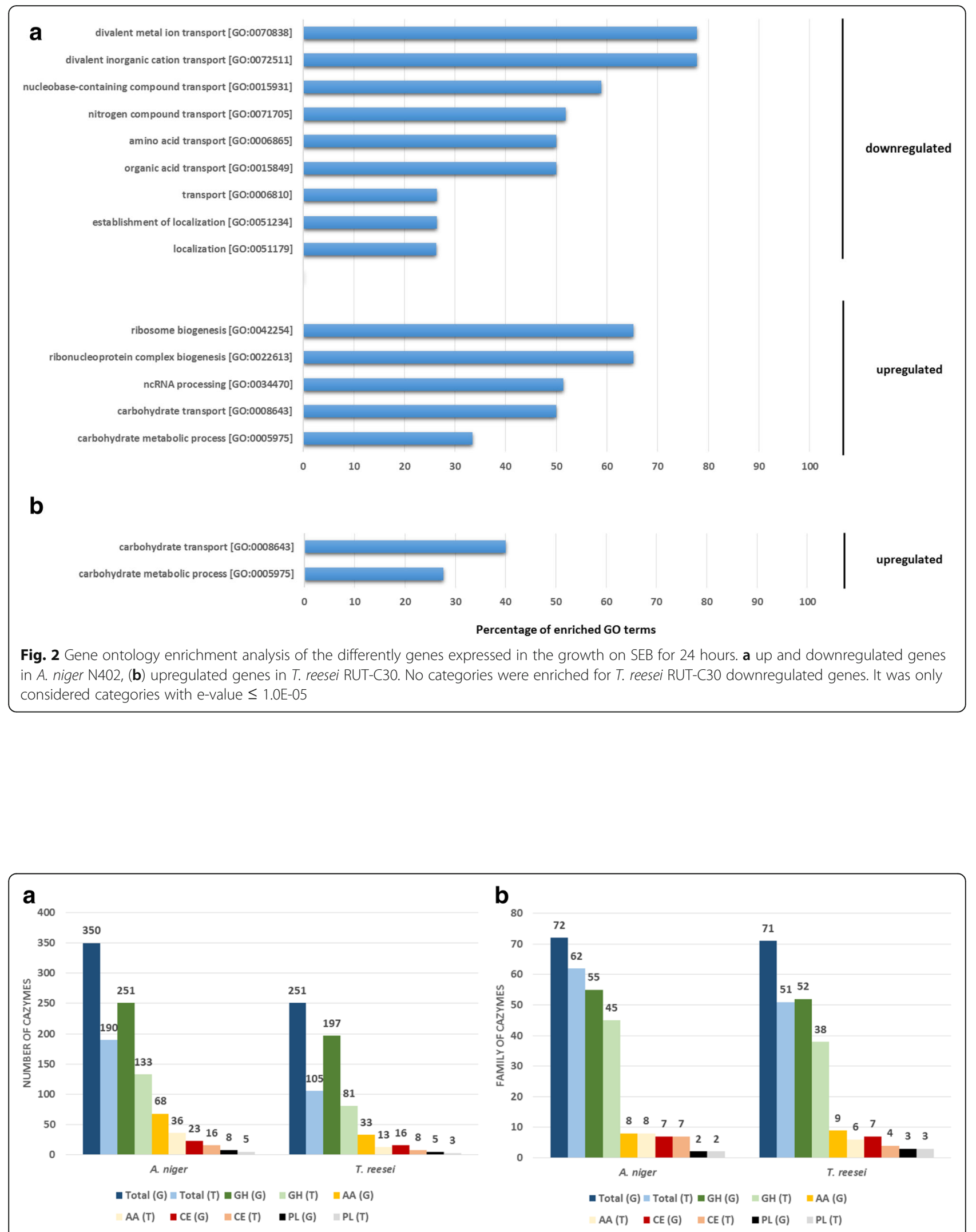

Fig. 3 Total number of CAZymes (excluding GT and CE10) (a) and their respective families (b) found in the genomes (G) and transcriptomes of $A$. niger N402 and T. reesei RUT-C30 grown on SEB (T) 
Previous papers have also assessed the transcriptional changes in these two fungi when growing on simple or complex carbon sources (Table 1). Despite differences in fungal growth and experimental design, the transcriptional changes observed could be also due to the composition of substrate utilized, as well as the severity of the pretreatment applied to biomass. We are presenting herein the first study that compares the transcriptional response of these two fungal strains when grown on SEB as sole carbon source. Steam-explosion induces changes in lignin structure, which coupled to partial hemicellulose hydrolysis, increases substantially the cellulosic fraction availability and as consequence, its hydrolysis [48]. As result, more sugars (polysaccharides, oligosaccharides and monomers) are released to the medium, what might thus induce the expression of a larger number of different CAZymes, than observed before. The transcriptional response of $A$. niger when grown on SEB was previously studied using microarray, revealing a smaller number of differentially expressed CAZymes [34] (67 genes, Table 1). This difference might result from the microarray platform having a narrower dynamic range for expression values in comparison to RNA-seq approaches [49].

Discrepancies were also found in relation to the temporality of gene expression. For A. niger, Delmas et al. [32] showed important genes related to biomass degradation being induced along their time series study. For instance, the cellobiohydrolase B (cbhB, An01g11660, GH7) and an arabinofuronosidase (abfB, An15g2300, GH54) were expressed after $6 \mathrm{~h}$ of growth in media with wheat straw, the cellobiohydrolase A (cbhA, An07g09330, GH7), one lytic polysaccharide monooxygenase (An12g04610, AA9) and one hydrophobin ( $h s b A$, An09g00840) after $12 \mathrm{~h}$, and another hydrophobin ( $h f b D$, An08g09880) only after $24 \mathrm{~h}$. We found these genes induced since $6 \mathrm{~h}$, with high values of $\log _{2}$ fold change and expression values (expression value RPKM; Additional file 4). Curiously, the only exception is the $\operatorname{cbh} A$ that was upregulated at 6 and $12 \mathrm{~h}$, but not at 24 h. Analyzing the raw data, this gene was highly expressed both in SEB and in fructose at $24 \mathrm{~h}$ (data not shown), but it was not differently regulated. In relation to $T$. reesei, Poggi et al. [50] showed a similar expression of the main CAZymes (cel5a, cel12a, cel45a, cel74a) during a time course (1, 3, 6 and 24 h) using lactose as inducer of cellulolytic gene expression. Some differences, such as the absence of $c e l 7 b$ in the latest time point in lactose, could be a signal saturation problem present in microarray analysis.

In addition to the disparities in the total number of differentially expressed CAZymes between $A$. niger and T. reesei, there are also important differences in the families that were being regulated (Additional file 4 and 5). Genes exclusively found induced in $A$. niger were from the families CE8 (An02g12505 and An04g09690), CE12 (An04g09360, An05g02270 and An09g02160),
PL1 (An10g00870, An11g04030, An14g04370 and An19g00270), PL4 (An14g01130), that play distinct roles in the breakdown of pectin, and GH51 ( $\alpha$-L-arabinofuranosidase) that hydrolyzes the glycosidic bond between L-arabinofuranosides side chains of hemicelluloses such as arabinoxylan (Table 2). Conversely, for T. reesei, the following families were exclusively induced in this microorganism: the GH45 endoglucanase (25940) that acts on the hydrolysis of soluble $\beta-1,4$ glucans, a CE15 glucuronoyl esterase (125575) and a GH115 xylan- $\alpha$-glucuronidase (25542) that can cleave glucuronic acid residues from xylan backbone (Table 3).

We were then interested in understanding the general expression profile of the CAZyme families related to biomass degradation (AA9, CE1, CE3, CE5, CE16, GH1, GH3, GH5, GH6, GH7, GH10, GH11, GH12, GH43, GH45, GH51, GH54, GH62, GH67, GH74, GH93, GH115 [51]). It could be observed that the two strains behaved in opposite ways: A. niger strongly induced the biomass degrading genes at the beginning $(6 \mathrm{~h})$ of the growth in SEB, and their expression decreased over time, while $T$. reesei had an increasing gene expression during the time course (Fig. 4a).

As the number of genes induced by each microorganism is different, we decided to focus on the candidate orthologues for these CAZymes (Additional file 6) and observed the same general trend (Fig. 4b). This trend was confirmed when looking at the individual CAZyme families (Additional file 7). This was further confirmed by RT-qPCR for some genes that encode essential enzymes to biomass degradation (Additional file 8 and 9), with significant Pearson correlations $(>0.95$ for the most genes). It is interesting that CAZymes from $A$. niger showed this decreasing expression from 6 to $24 \mathrm{~h}$. This gene profile was already reported by Souza et al. [34] and might represent a standard mechanism in this strain to act upon contact with complex biomass sources, and a different control in the expression of these enzymes in relation to $T$. reesei strain.

When looking at the 20 most strongly induced genes in T. reesei, it was noticeable that since the early time point $(6 \mathrm{~h})$, the majority of them correspond to CAZymes important to the carbon degradation, such as GH10, GH11, CE1, GH6, GH62 and others (Additional file 10). The expression of most of them increased during the time course. However, curiously, the transcriptional response of $A$. niger grown on bagasse was dramatically different; the CAZymes were prevalent only in the earliest time point and, as showed above for the main families, their expression decreased during the time course (Additional file 11, 7, 8). Despite the prevalence of CAZymes among the 20 most strongly induced genes in $T$. reesei, the average expression level was two times higher in $A$. niger at the time points 6 and $12 \mathrm{~h}$ (Additional file 11). We also noticed 
Table 2 The main CAZymes related to biomass deconstruction upregulated in A. niger N402 transcriptome

\begin{tabular}{|c|c|c|c|c|c|c|c|c|}
\hline \multirow[t]{2}{*}{ ID AspGDa } & \multirow[t]{2}{*}{ Description $^{a}$} & \multirow[t]{2}{*}{ Gene name } & \multirow[t]{2}{*}{ CAZy Family } & \multirow[t]{2}{*}{ Peptide Signal $^{b}$} & \multicolumn{3}{|c|}{$\log _{2} \mathrm{FC}^{\mathrm{C}}$} & \multirow[t]{2}{*}{ Predicted substrate } \\
\hline & & & & & $6 \mathrm{~h}$ & $12 \mathrm{~h}$ & $24 h$ & \\
\hline An16g00060 & Hypothetical protein & - & CE1 & $\mathrm{N}$ & 3.32 & 3.09 & 4.91 & Unknown \\
\hline An08g05230 & $\begin{array}{l}\text { Lytic polysaccharide } \\
\text { monooxygenase }\end{array}$ & - & AA9 & Y & 2.24 & 1.55 & - & Cellulose \\
\hline An12g02540 & $\begin{array}{l}\text { Lytic polysaccharide } \\
\text { monooxygenase }\end{array}$ & - & AA9 & Y & 5.41 & 6.57 & 3.30 & Cellulose \\
\hline An12g04610 & $\begin{array}{l}\text { Lytic polysaccharide } \\
\text { monooxygenase }\end{array}$ & - & AA9 & Y & 8.49 & 8.35 & 4.82 & Cellulose \\
\hline An14g02670 & $\begin{array}{l}\text { Lytic polysaccharide } \\
\text { monooxygenase }\end{array}$ & - & $\mathrm{AA9}, \mathrm{CBM} 1$ & Y & 1.71 & - & - & Cellulose \\
\hline An15g04900 & $\begin{array}{l}\text { Lytic polysaccharide } \\
\text { monooxygenase }\end{array}$ & - & $\mathrm{AA9}, \mathrm{CBM} 1$ & Y & 2.16 & 1.80 & - & Cellulose \\
\hline An09g00120 & Feruloyl esterase & faeA & CE1 & Y & 7.80 & 6.93 & 5.95 & $\begin{array}{l}\text { Arabinoxylan, } \\
\text { pectin }\end{array}$ \\
\hline An12g05010 & Acetyl xylan esterase & axeA & CE1 & Y & 8.22 & 6.63 & 5.68 & Xylan \\
\hline An12g02550 & Feruloyl esterase & - & CE1 & Y & 8.15 & 7.38 & 5.12 & Xylan, pectin \\
\hline An07g03100 & Putative esterase $\mathrm{E}$ & - & CE1 & N & 1.04 & - & - & Unknown \\
\hline An07g08940 & $\begin{array}{l}\text { Cellulose-binding GDSL } \\
\text { lipase/acylhydrolase }\end{array}$ & - & CE16 & Y & 6.73 & 5.21 & 3.94 & Xylan, mannan \\
\hline An14g02170 & Cutinase 1 & - & CE5 & Y & 2.97 & 2.99 & 1.34 & Cutin \\
\hline An11g00110 & Cutinase 2 & - & CE5 & Y & 1.84 & 1.28 & 1.72 & Cutin \\
\hline An03g03740 & B-glucosidase & $b g / 4$ & $\mathrm{GH} 1$ & $N$ & 2.82 & 1.87 & - & Cellulose \\
\hline An04g03170 & B-glucosidase & - & $\mathrm{GH} 1$ & Y & 6.95 & 4.53 & 5.27 & Cellulose \\
\hline An11g02100 & B-glucosidase & - & $\mathrm{GH} 1$ & Y & 6.30 & 5.44 & 4.86 & Cellulose \\
\hline An03g00940 & Endoxylanase & $x y n A$ & $\mathrm{GH} 10$ & Y & 7.90 & 6.38 & 5.00 & Xylan \\
\hline An01g00780 & Endoxylanase & $x y n B$ & $\mathrm{GH} 11$ & Y & 9.42 & 7.71 & 6.21 & Xylan \\
\hline An15g04550 & Endoxylanase & xynV & GH11 & Y & 4.15 & 2.40 & 1.73 & Xylan \\
\hline An14g02760 & Endoglucanase & eg/A & $\mathrm{GH} 12$ & Y & 9.02 & 7.58 & 4.78 & Cellulose \\
\hline An01g03340 & $\begin{array}{l}\text { Xyloglucan active } \\
\text { endoglucanase }\end{array}$ & - & $\mathrm{GH} 12$ & Y & 5.48 & 4.43 & 3.20 & Cellulose \\
\hline An11g06080 & B-glucosidase & - & $\mathrm{GH} 3$ & $\mathrm{~N}$ & 3.95 & 3.19 & 1.90 & Cellulose \\
\hline An11g06090 & $\begin{array}{l}\text { Candidate } \\
\beta \text {-glucosidase }\end{array}$ & - & $\mathrm{GH} 3$ & Y & 3.76 & 3.34 & 2.20 & Cellulose \\
\hline An02g07590 & $\begin{array}{l}\text { Candidate } \\
\beta \text {-glycosidase related } \\
\text { to } \beta \text {-N-acetylhexosaminidase }\end{array}$ & - & $\mathrm{GH} 3$ & N & - & - & 1.01 & Unknown \\
\hline An07g07630 & B-glucosidase & - & $\mathrm{GH} 3$ & Y & 6.32 & 5.45 & 5.02 & Starch \\
\hline An11g00200 & B-glucosidase & - & $\mathrm{GH} 3$ & Y & 7.44 & 6.38 & 6.21 & Cellulose \\
\hline An14g01770 & B-glucosidase & - & $\mathrm{GH} 3$ & Y & 1.78 & 1.24 & - & Cellulose \\
\hline An15g04800 & B-glucosidase & - & $\mathrm{GH} 3$ & Y & 1.48 & - & 1.73 & Cellulose \\
\hline An17g00520 & B-glucosidase & - & $\mathrm{GH} 3$ & $N$ & 5.69 & 4.43 & 1.67 & Cellulose \\
\hline An18g03570 & B-glucosidase & $b g / A$ & $\mathrm{GH} 3$ & Y & 6.38 & 5.72 & 4.60 & Cellulose \\
\hline An01g09960 & B-xylosidase & $x \ln D$ & $\mathrm{GH} 3$ & Y & 8.24 & 6.05 & 4.47 & Xylan, pectin \\
\hline An17g00300 & $\begin{array}{l}\text { B-xylosidase/ } \\
\text { a-arabinofuranosidase }\end{array}$ & $x a r B$ & $\mathrm{GH} 3$ & Y & 6.10 & 4.39 & 3.49 & Xylan, pectin \\
\hline An02g10550 & Endoarabinanase & $a b n C$ & $\mathrm{GH} 43$ & Y & 5.63 & 5.26 & 5.09 & Pectin \\
\hline An09g01190 & Endoarabinanase & $a b n A$ & $\mathrm{GH} 43$ & Y & 5.14 & 4.47 & 2.93 & Pectin \\
\hline An15g03550 & Endoarabinanase & - & $\mathrm{GH} 43$ & Y & 8.24 & 7.84 & 6.12 & Pectin \\
\hline
\end{tabular}


Table 2 The main CAZymes related to biomass deconstruction upregulated in A. niger N402 transcriptome (Continued)

\begin{tabular}{|c|c|c|c|c|c|c|c|c|}
\hline An08g01900 & B xylosidase & - & $\mathrm{GH} 43$ & Y & 5.43 & 4.17 & 4.71 & Xylan \\
\hline An02g00140 & B-xylosidase & - & $\mathrm{GH} 43$ & N & 4.41 & 3.39 & 4.14 & Xylan \\
\hline An11g03120 & B-xylosidase & $x y n D$ & $\mathrm{GH} 43$ & Y & 3.55 & 3.20 & 2.56 & Xylan, pectin \\
\hline An18g03330 & Exo-1,3-galactanase & - & GH5 & N & 1.17 & 1.38 & - & $\beta-1,3-G l u c a n$ \\
\hline An07g08950 & Endoglucanase & eg/C & GH5 & Y & 5.46 & 4.22 & 2.19 & Cellulose \\
\hline An06g02060 & Exo-1,3-galactanase & - & GH5 & Y & 1.18 & - & 1.35 & Cellulose \\
\hline An18g04100 & Exo-1,3-galactanase & $\operatorname{exg} A$ & GH5 & Y & 4.46 & 5.19 & 5.08 & $\beta-1,3-G l u c a n$ \\
\hline An03g01050 & Exo-1,6-galactanase & - & GH5 & Y & 2.93 & - & - & Cellulose \\
\hline An01g11670 & Endoglucanase & - & GH5, CBM1 & Y & 8.00 & 6.48 & 4.22 & Cellulose \\
\hline An08g01710 & a- arabinofuranosidase & $a b f c$ & GH51 & $\mathrm{N}$ & 4.61 & 3.73 & 3.91 & $\begin{array}{l}\text { Xyloglucan, } \\
\text { xylan, pectin }\end{array}$ \\
\hline An15g02300 & a-arabinofuranosidase & $a b f B$ & GH54, CBM42 & Y & 6.04 & 3.81 & 1.03 & $\begin{array}{l}\text { Xyloglucan, } \\
\text { xylan, pectin }\end{array}$ \\
\hline An08g01760 & Cellobiohydrolase & - & GH6 & Y & 9.03 & 7.97 & 5.43 & Cellulose \\
\hline An12g02220 & Cellobiohydrolase & - & GH6, CBM1 & Y & 11.59 & 10.76 & 7.40 & Cellulose \\
\hline An03g00960 & $\begin{array}{l}\text { Arabinoxylan } \\
\text { arabinofuranohydrolase }\end{array}$ & $\operatorname{axhA}$ & GH62 & $\mathrm{N}$ & 7.52 & 6.18 & 4.95 & Xylan \\
\hline An14g05800 & a-glucuronidase & $\operatorname{aguA}$ & GH67 & Y & 7.51 & 5.50 & 4.83 & Xylan \\
\hline An07g09330 & Cellobiohydrolase & $\operatorname{cbh} A$ & $\mathrm{GH} 7$ & Y & 4.36 & 4.71 & - & Cellulose \\
\hline An01g11660 & Cellobiohydrolase & $c b h B$ & $\mathrm{GH} 7, \mathrm{CBM} 1$ & Y & 8.45 & 6.69 & 3.08 & Cellulose \\
\hline An01g01870 & Xyloglucan active endoglucanase & $\mathrm{eg} / \mathrm{C}$ & GH74, CBM1 & Y & 1.67 & 1.67 & - & Cellulose \\
\hline
\end{tabular}

${ }^{\mathrm{a}}$ The Aspergillus Genome Database was used to recover the A. niger proteins ID and description; ${ }^{\mathrm{b}}$ The presence of signal peptide was predicted by SignalP 4.1 Server; ${ }^{\mathrm{C}} \log _{2}$ fold change

that $A$. niger N402 and T. reesei RUT-C30 induced a central set of shared genes coding for the most important CAZymes (such as $\beta$-glucosidases, cellobiohydrolases, endoglucanases, xylanases, $\beta$-xylosidases, lytic polysaccharide monooxygenases (LPMOs)) that are activated by a variety of lignocellulosic substrates, but have different strategies to degrade biomass.

Among the main CAZymes, AA enzymes have been the focus of several recent studies, with special highlight to the LPMOs (AA9, AA10, AA11 and AA13), as they can be involved in the oxidative breakdown of cellulose, hemicellulose and lignin [52], as well as in the biotransformation or detoxification of lignocellulosic compounds [53]. It is important to note here that $A$. niger has a considerable larger number of AAs compared to $T$. reese $i$ (68 vs 33), showing the largest difference of all CAZymes between the two strains. Few studies have been published for AAs in these saprophytic fungi. Only AA9 (former GH61) was characterized in T. reesei [54-56], and two glucose oxidase (AA3) have been studied in $A$. niger [57-59]. Nevertheless, our data suggest they might have an important role on biomass degradation since $53 \%$ e $39 \%$ of all AAs found in A. niger and T. reesei genomes, respectively, were induced by growth in SEB in both strains.

Five AA9-coding genes (An08g05230, An12g02540, An12g04610, An14g02670 and An15g04900) were upregulated in $A$. niger and they had their highest expression at $6 \mathrm{~h}$ (Table 2 and Additional file 4), with exception of one gene (An12g04610), which expression decreased during the time course. In contrast, the two AA9 upregulated genes of T. reesei (139633 and 122518) showed an increasing expression during the later periods of the time course, reaching notable fold change values (386 and 543 times, respectively) at $24 \mathrm{~h}$ (Table 3 and Additional file 5). We could predict orthologues of the T. reesei 139633 gene in $A$. niger, genes An12g04610 and An14g02670, with both of these presenting different expression profiles (Additional file 6). As mentioned before, these differences were also observed to the gene expression profile of other CAZymes (GHs and CEs) in both fungal strains (Fig. 4a).

LPMOs have three different electron transfer systems [60]. The systems 1 and 2 reduce indirectly the active site of LPMOs by transferring electrons through the cytochrome domain of cellobiose dehydrogenase $(\mathrm{CDH}$; AA3.1) or by fungal and plant-derived LPMO-reducing phenols, respectively. The third system is comprised of GMC oxidoreductases (Glucose-Methanol-Choline oxidoreductases; AA3.2 and AA3.3) that regenerate those phenolic compounds to reduce the LPMO [60]. A. niger has one gene coding for a putative CDH (An02g09270), however it was not found induced in the conditions assayed here; moreover, $T$. reesei genome does not have 
Table 3 The main CAZymes related to biomass deconstruction upregulated in T. reesei RUT-C30 transcriptome

\begin{tabular}{|c|c|c|c|c|c|c|c|c|}
\hline \multirow[t]{2}{*}{$|D J G|^{*}$} & \multirow[t]{2}{*}{ Description $^{a}$} & \multirow[t]{2}{*}{ Gene name } & \multirow{2}{*}{$\begin{array}{l}\text { CAZy } \\
\text { Family }\end{array}$} & \multirow[t]{2}{*}{ Peptide Signal $^{b}$} & \multicolumn{3}{|c|}{$\log _{2} \mathrm{FC}^{\mathrm{C}}$} & \multirow[t]{2}{*}{ Predicted substrate } \\
\hline & & & & & $6 \mathrm{~h}$ & $12 \mathrm{~h}$ & $24 \mathrm{~h}$ & \\
\hline 122518 & Lytic polysaccharide monooxygenase & cel61b & AA9 & Y & 3.23 & 6.54 & 9.09 & Cellulose and $\beta$-glucan \\
\hline 139633 & Lytic polysaccharide monooxygenase & cel61a, eg/4 & AA9, CBM1 & Y & 3.84 & 6.10 & 8.59 & Cellulose and $\beta$-glucan \\
\hline 136770 & Acetyl esterase & aes1 & CE16 & Y & 6.33 & 7.50 & 7.74 & Xylan \\
\hline 5643 & Candidate acetyl esterase & - & CE16 & Y & 1.30 & 1.45 & 1.07 & Xylan \\
\hline 128705 & Candidate acetyl xylan esterase & - & CE3 & $\mathrm{N}$ & 1.60 & 1.82 & 1.55 & Xylan \\
\hline 35989 & Candidate acetyl xylan esterase & - & CE3 & N & - & - & 1.34 & Xylan \\
\hline 134377 & Candidate acetyl xylan esterase & - & CE3 & $\mathrm{N}$ & 2.82 & 3.01 & 3.00 & Xylan \\
\hline 88887 & Candidate acetyl xylan esterase & - & CE5 & N & 4.83 & 6.01 & 8.93 & Xylan \\
\hline 139631 & Acetyl xylan esterase & axe1 & CE5, CBM1 & Y & 4.44 & 6.46 & 9.12 & Xylan \\
\hline 127115 & $\beta$-glucosidase & bgl2, cella & $\mathrm{GH} 1$ & N & 3.78 & 4.57 & 5.96 & Cellulose and $\beta$-glucan \\
\hline 77989 & Candidate $\beta$-glucosidase & cel1b & $\mathrm{GH} 1$ & $\mathrm{~N}$ & 1.78 & 2.42 & 2.83 & Cellulose and $\beta$-glucan \\
\hline 23616 & Endo- $\beta-1,4$-xylanase & xyn3 & $\mathrm{GH} 10$ & Y & 2.69 & 4.78 & 8.53 & Xylan \\
\hline 124931 & Endo- $\beta-1,4$-xylanase & xyn2 & GH11 & Y & 6.38 & 7.56 & 8.91 & Xylan \\
\hline 134945 & Candidate endo- $\beta-1,4$-xylanase & xyn5 & $\mathrm{GH} 11$ & $\mathrm{~N}$ & 5.54 & 6.06 & 6.80 & Xylan \\
\hline 38418 & Endo- $\beta-1,4$-xylanase & xyn 1 & $\mathrm{GH} 11$ & Y & 2.01 & 3.00 & 2.73 & Xylan \\
\hline 25542 & $\begin{array}{l}\text { Candidate xylan-a-1,2-glucuronidase/ } \\
\text { a-(4-O-methyl)-glucuronidase }\end{array}$ & - & GH115 & $\mathrm{N}$ & - & 1.11 & - & Xylan \\
\hline 124438 & Endo- $\beta$-1,4-glucanase & egl3, cel12a & $\mathrm{GH} 12$ & Y & 1.74 & 5.38 & 8.96 & Cellulose and $\beta$-glucan \\
\hline 140746 & $\beta$-xylosidase & $b \times 11$ & $\mathrm{GH} 3$ & Y & 7.84 & 7.57 & 8.25 & Xylan \\
\hline 25095 & Candidate $\beta$-glucosidase & cel3b & $\mathrm{GH} 3$ & Y & - & - & 1.10 & Cellulose and $\beta$-glucan \\
\hline 125268 & Candidate $\beta$-glucosidase & $\mathrm{cel} 3 \mathrm{C}$ & $\mathrm{GH} 3$ & N & 2.35 & 3.21 & 4.31 & Cellulose and $\beta$-glucan \\
\hline 136547 & $\beta$-glucosidase & bgl1/cel3a & $\mathrm{GH} 3$ & $\mathrm{~N}$ & 1.75 & 3.61 & 7.14 & Cellulose and $\beta$-glucan \\
\hline 122639 & Candidate $\beta$-glucosidase & cel3d & $\mathrm{GH} 3$ & $\mathrm{~N}$ & 3.23 & 4.17 & 5.76 & Cellulose and $\beta$-glucan \\
\hline 74305 & Candidate $\beta$-glucosidase & cel3e & $\mathrm{GH} 3$ & Y & 1.31 & 1.36 & 1.51 & Cellulose and $\beta$-glucan \\
\hline 82126 & $\begin{array}{l}\text { Cand. } \beta \text {-glucosidase/ } \\
\text { glucan 1,4- } \beta \text {-glucosidase }\end{array}$ & $b g / 3 f$ & $\mathrm{GH} 3$ & Y & 2.52 & 3.41 & 5.15 & Cellulose and $\beta$-glucan \\
\hline 74129 & Candidate $\beta$-xylosidase & $x y \mid 3 b$ & $\mathrm{GH} 3$ & $\mathrm{~N}$ & 2.12 & 2.70 & 1.99 & Xylan \\
\hline 77521 & $\begin{array}{l}\text { Candidate } \beta \text {-xylosidase/ } \\
\text { a-L-arabinofuranosidase }\end{array}$ & - & $\mathrm{GH} 43$ & $\mathrm{~N}$ & 4.21 & 4.76 & 5.31 & Others \\
\hline 25940 & Endo- $\beta-1,4$-glucanase & egl5, cel45a & GH45, CBM1 & Y & 2.95 & 5.41 & 8.52 & Cellulose and $\beta$-glucan \\
\hline 72489 & Endo- $\beta$-1,4-glucanase & egl2, cel5a & $\mathrm{GH} 5, \mathrm{CBM} 1$ & Y & 3.27 & 5.74 & 8.57 & Cellulose and $\beta$-glucan \\
\hline 122377 & $\beta$-Mannanase & man1 & GH5, CBM1 & Y & 2.52 & 4.86 & 8.77 & $\begin{array}{l}\text { Mannan and } \\
\text { galactomannan }\end{array}$ \\
\hline 102517 & a-L-arabinofuranosidase I & $a b f 1$ & GH54, CBM42 & Y & 2.55 & 1.51 & - & Xylan \\
\hline 122470 & Cellobiohydrolase & cbh2, cel6a & GH6, CBM1 & Y & 2.73 & 5.28 & 8.24 & Cellulose and $\beta$-glucan \\
\hline 118070 & Candidate $\mathrm{a}$ - $\mathrm{L}$-arabinofuranosidase & $a b f 2$ & GH62 & Y & 5.88 & 4.90 & 7.03 & Xylan \\
\hline 90302 & a-Glucuronidase & glr1 & GH67 & Y & 6.96 & 7.33 & 7.62 & Xylan \\
\hline 125125 & Cellobiohydrolase & cbh1, cel7a & $\mathrm{GH} 7, \mathrm{CBM} 1$ & Y & 3.49 & 5.84 & 8.75 & Cellulose and $\beta$-glucan \\
\hline 5304 & Endo- $\beta$-1,4-glucanase & egll, cel7b & GH7, CBM1 & Y & 2.63 & 5.05 & 8.39 & Cellulose and $\beta$-glucan \\
\hline 111943 & Xyloglucanase & cel74a & GH74, CBM1 & Y & 2.04 & 2.18 & 3.87 & Xyloglucan \\
\hline
\end{tabular}

${ }^{\mathrm{a}}$ Trichoderma reesei RUT C30 v1.0 database from JGI was used to recover the T. reesei proteins ID and description; ${ }^{\mathrm{b}}$ The presence of signal peptide was predicted by SignalP 4.1 Server; ${ }^{\mathrm{C}} \log _{2}$ fold change

a $c d h$ gene. Conversely, several genes coding AA3.2 and AA3.3 (alcohol oxidase, aryl-alcohol oxidase, glucose oxidase, Additional file 4 and 5) were induced by SEB in both fungi. These oxidative enzymes are responsible for hydrogen peroxide and oxygen radicals formation, that are reactive molecules that can attack the polysaccharides 

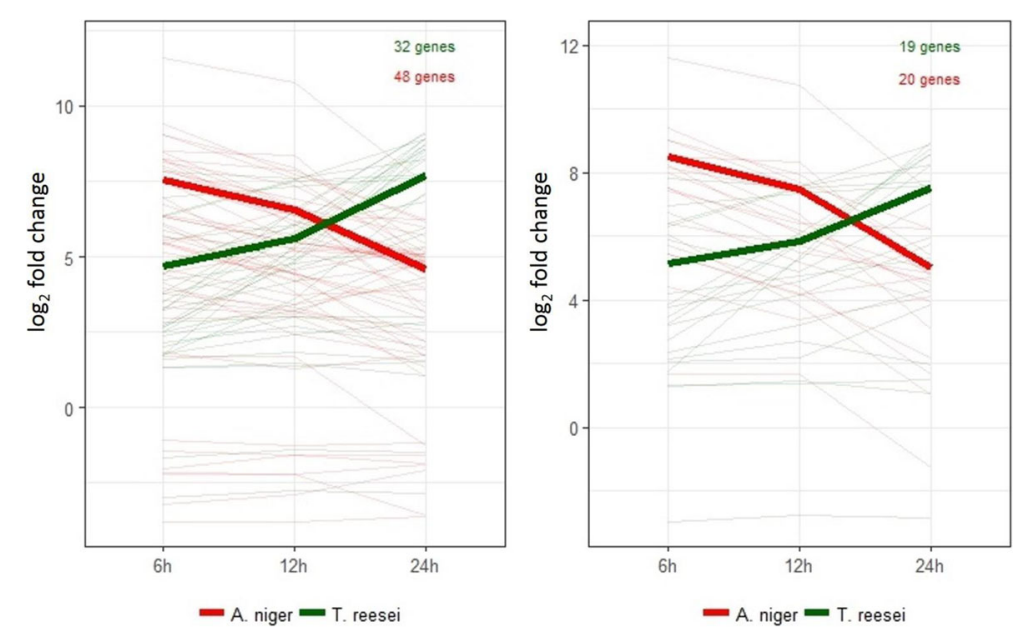

Fig. 4 Expression profile of the genes belonging to the main CAZyme families related to biomass deconstruction in A. niger N402 and T. reesei RUT-C30. A) Average of $\log _{2}$ (fold changes) from all genes listed in Table 1 and Table 2. B) Average of $\log _{2}$ (fold changes) of the predicted orthologues genes (listed in Additional file 6). Thinner lines represent the individual gene expression (log (fold change)) for each fungus and the thicker ones the average of these values. Only genes upregulated in all time points (6, 12 and $24 \mathrm{~h})$ were considered

and lignin components of lignocellulose [61]. Then, although the oxidative degradation of lignocellulose has not been investigated, our data allows to hypothesize that both fungal strains could employ enzymatic and non-enzymatic redox reactions to break down the lignocellulose.

Beyond the annotated CAZymes, 15 upregulated genes were found with significant CAZy domains (e-value $<1.00 \mathrm{E}-17$ and coverage $>0.45)$ in A. niger (12 AA, $2 \mathrm{CE}$ e $1 \mathrm{GH}$ ) and only 2 to $T$. reesei (2 AA) (Additional file 12 ). Most of these genes were expressed at all time points analyzed; however, whether these proteins represent new CAZymes, still needs to be investigated.

\section{Transporters}

Both fungi have a similar number of transporters: the genome of $A$. niger has 865 transporter-coding genes [62] and T. reesei has 816 [63]. In A. niger 174 genes annotated as sugar transporters or without predicted substrate were upregulated (Additional file 13). About half of them were strongly (five to ten times) induced in SEB at all time points. In $T$. reesei 83 transporters were induced in SEB (Additional file 14). The expression profile during the time course was similar between both fungi (Fig. 5a), the fold changes decreased at $12 \mathrm{~h}$, increasing at $24 \mathrm{~h}$, which clearly contrasts with the expression profiles of CAZymes related to biomass deconstruction (Fig. 4). Although some sugar transporters are known to be regulated by transcription factors that regulate CAZymes as well $[34,64]$, the observed differences between the expression profiles of transporters and CAZymes suggest that different set of regulators might be controlling the expression of these genes.
These transporters are proteins to be studied in relation to their potential of transport sugars released from vegetal biomass, such as xylose, cellobiose, and arabinose and can be used to the genetic engineering of industrial strain applied in different industrial fermentations $[65,66]$. Recently, Sloothaak et al. [67] applied a pipeline to identify putative xylose transporters to the in silico deduced proteomes of $T$. reesei and $A$. niger. From the top 15 highest scoring proteins found in each genome, only four genes were found as being upregulated in T. reesei, including str1 (138519) and str2 (136712) that were characterized as xylose transporters. In relation to A. niger, eight putative xylose transporter genes were found upregulated, including $x l t B$ (An11g05280). The product of $x l t B$ transports xylose with the highest specificity described so far [67].

Additionally, recently some transporters have been reported to be involved in the induction of CAZymes [46, 47, 68]. For instance, crt1 (109243) and str1 (138519) transporters-coding genes of $T$. reesei were strongly activated by SEB at all time points (Additional file 14), with special attention to the increasing expression profile of $c r t 1$ ( $\log _{2}$ (fold change): $6 \mathrm{~h}: 5.46 ; 12 \mathrm{~h}$ : 6.47; 24 h: 7.54). It was showed that Crt1 is a lactose permease essential for cellulase induction [68] while Str1 is crucial for pentose utilization and has a role on xylanase induction [47]. Thus, other proteins encoded by these upregulated genes can be potential candidates to sense and transduce signals related to biomass deconstruction and thus potential targets for strain improvement.

We identified 43 groups of candidate orthologues genes between $A$. niger and $T$. reesei that have at least one gene upregulated in our dataset (Additional file 15). 


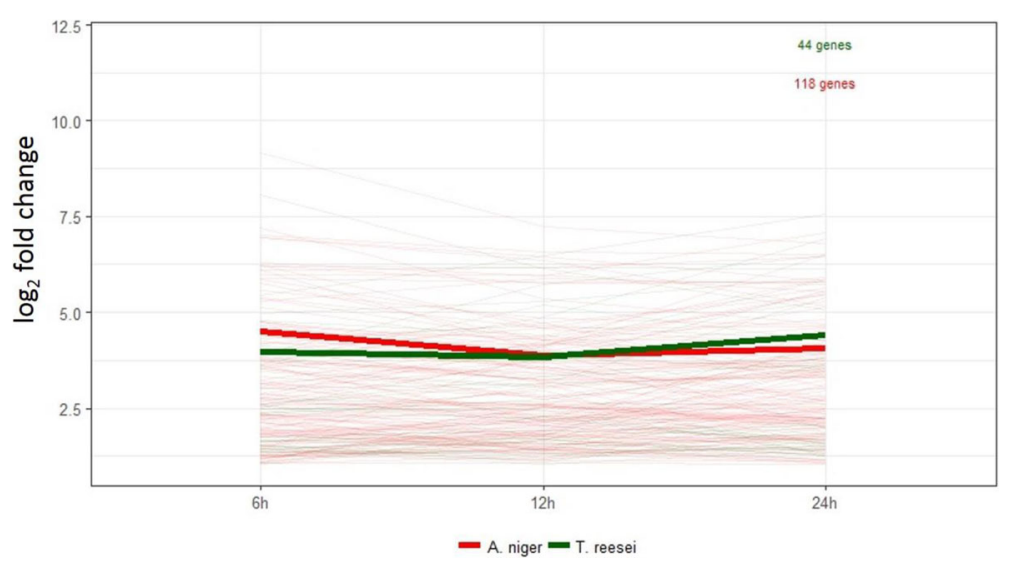

Fig. 5 Expression profile of genes encoding transporters in A. niger N402 and T. reesei RUT-C30 transcriptomes. Average of log 2 (fold change) from all genes listed in Additional file 13 and 14. Thinner lines represent the individual gene expression ( $\log _{2}($ fold change)) for each fungus and the thicker ones the average of these values. Only genes upregulated in all time points $(6,12$ and $24 \mathrm{~h}$ ) were considered

We observed contrasting expression profiles among the genes in these groups of orthologues. For instance, the pair of predicted orthologues genes An03g01620 in $A$. niger and 33630 in $T$. reesei, both are annotated as sugar transporters, the former as a putative high affinity glucose transporter (AspGD) and the latter as a xylose transporter [69]; only the T. reesei gene was found induced by SEB, at all time points (Additional file 15). Another example is found with the pair An18g01700 ( $A$. niger) and 85254 (T. reesei). An18g01700 is the predicted orthologue of the Saccharomyces cerevisiae Hxt8-coding gene and we found it among the SEB induced genes; however, the respective $T$. reesei orthologue did not respond to SEB. These observations strengthen the idea that the two strains have different mechanisms for lignocellulosic biomass degradation.

We also identified several additional upregulated transcripts in both fungal strains that were described as transporters of compounds such as ions, amino acids, and peptides (81 in A. niger and 68 in T. reesei, Additional file 16). It is worth noting that iron and siderophore transport genes were induced, with considerably larger fold changes in T. reesei (Additional file 16). The iron cation is required in Fenton reactions that produce hydroxyl radicals, which can help disrupt lignocellulose [70]. Alternatively, inducing iron transport can be trigger by the depletion of this cation as it binds to cellulose [41]. These observations highlight the fact that not only sugar-degradation and assimilation metabolic pathways are modulated during biomass degradation.

\section{Transcription factors}

Expression and secretion of CAZymes and other enzymes and proteins required for biomass deconstruction are energy-demanding processes. Thus, they will only be produced at a higher quantity when fungi sense the polysaccharides from available plant biomass, and no alternative carbon sources are available, consequently minimizing energy demands. Although the complete mechanisms for the regulation of this process remains unclear, it is known that it is driven by transcription factors (TFs).

In this section we paid attention to TF genes as described by Pel et al. [62] for A. niger and by the Schmoll et al. [71] for T. reesei. In total, 152 upregulated TFs were found in A. niger (Additional file 17) and 52 in T. reesei (Additional file 18), most of them not been functionally characterized so far. Twenty-three TF genes have been previously described as being related to biomass deconstruction (Table 4), for 13 of these we found candidate orthologues in both fungal strains, four were only present in $A$. niger, five only in $T$. reesei and one was not found in either strains (galR, described in A. nidulans [72]). Only two out of the $13 \mathrm{TF}$ genes found in both fungi were induced by SEB ( $x l y R / x y r 1$ and malR), but they had distinct expression patterns. In $A$. niger, the expression of these two regulators was upregulated at all time points, similar to the expression profiles of the CAZymes (Fig. 4), $i$ e., decreasing the expression during the time course (Table 4). In T. reesei, the expression of CAZymes was detected since the early time points and raised up to $24 \mathrm{~h}$ and the major activator xyr 1 was only found induced at 24 $\mathrm{h}$ ( $\log _{2}$ (fold change): 1.65). Xyrl was expressed at a higher level when $T$. reesei grown on SEB than fructose, during the entire time course; however, at early time point the differences in expression values was below our chosen threshold ( $\log _{2}$ (fold change): 6 h: 0.49; 12 h: 0.99). The TF malR has been described as being induced by maltose and as responsible for the expression of the maltose-utilizing gene cluster[73]; why this regulator is induced in both fungi is intriguing, as the SEB did not have a significant quantity of this sugar $[74,75]$. 


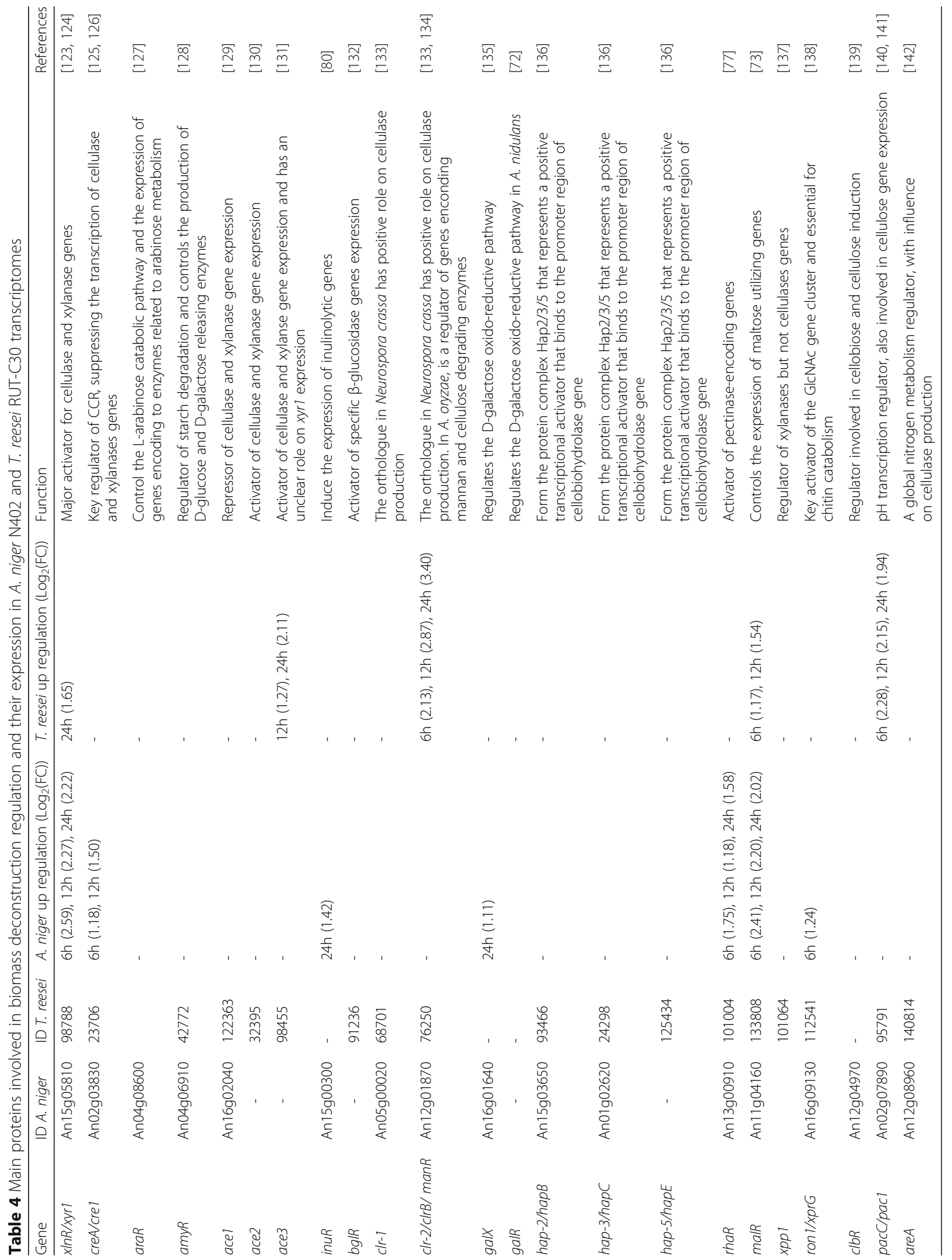


We also found that the transcriptional activator rhaR, involved in pectin degradation, was induced in $A$. niger. The sugarcane cell wall has a low proportion of pectin $(\sim 10 \%)$, and while most of that should be solubilized and washed-out during the steam-explosion used as pretreatment [75], some can remain available and used by the fungi. Particularly, A. niger is known as a good producer of pectinase [76] and in a previous study we observed that several pectinases were secreted when A. niger grew on SEB [44]. In our transcriptomics dataset we found 35 pectin-deconstruction genes induced in SEB, which are $60.3 \%$ of all the genes related to pectin-deconstruction found in the genome of $A$. niger [76] (Additional file 4); rhaR, the pectinase transcriptional activator [77], was found induced at all time points (An13g00910; $\log _{2}$ (fold change): 6 h: 1.75; 12 h: 1.18; 24 h: 1.58) (Table 4). The predicted T. reesei rhaR-orthologue (101004) was not induced in SEB and few pectinases were upregulated in this carbon source (Additional file 5).

The carbon catabolite repressor creA in $A$. niger (An02g03830) was upregulated at the initial time points in SEB (6 and $12 \mathrm{~h}$ ). In A. nidulans CreA mediates the repression of $x \ln R$, and in $A$. niger the expression of cre $A$ is associated to the repression of cellulases and hemicellulases, including the major activator $x \ln R$ (An15g05810) [78, 79]. Surprisingly, we also found $x \ln R$ to be induced since the earliest time point, suggesting a more complex regulatory relationship between $c r e A$ and $x \ln R$ in $A$. niger. In T. reesei, Ace3 (98455) positively regulates the expression of cellulases, and we found this gene induced at $12 \mathrm{~h}$ and $24 \mathrm{~h}$. xpp1 (101064), a positive regulator of xylanase expression, was downregulated at the early time points, with no significant difference in expression between SEB and fructose at $24 \mathrm{~h}$ ( $\log _{2}$ (fold change): 6 h, -1.47; 12 h, -2.53; 24 h, 0.02). Cre1 (23706) was slightly downregulated, with a fold change smaller than our selection criterion. In relation to other predicted TFs orthologues, we found four pairs of orthologues upregulated in both strains (An18g05600/ 77124, An16g06780/ 67125, An11g03890/ 39977, An09g01870/ 93861), and despite this interesting result, their functions remain to be elucidated.

The results presented above on TF genes, relied on previous identification of TFs [62, 71]. We decided to look for the genes that have protein domains frequently associated with transcription factor activity but that have not been identified as such in previous studies. Several induced putative TF genes were identified in both fungi with domain frequently associated to transcription factors (Additional file 19), such as fungal specific transcription factor domain (PF04082, PF11951), bZIP (PF00170), Fungal Zn(2)-Cys(6) binuclear cluster domain (PF00172). In this source, we identified inuR and rhaR that have not been described by Pel et al. [62], but that were characterized by Yuan et al. [80] and Gruben et al. [77], respectively. Therefore, further studies are necessary to elucidate their role in the regulation of lignocellulose degradation.

Although $A$. niger and $T$. reesei share some TFs of recognized importance in lignocellulose degradation (such as $\mathrm{X} \ln \mathrm{R} / \mathrm{Xyr} 1$ and $\mathrm{CreA} / \mathrm{Cre} 1$ ), they have clear differences concerning TF content and in their regulation of these genes. This clearly suggests that these two strains have different regulatory circuits at play for the degradation of complex biomass sources. A better understanding of these regulatory circuits is required to improve the genetic manipulation of these organisms, so that new strains can be generated with enhanced enzymatic potential.

\section{Other genes of interest}

The process of biomass saccharification releases different sugars to the environment. This leads to the induction of several genes in an array of sugar metabolic pathways, for instance in the arabinose and xylose metabolic pathways, the genes coding for D-xylose/xylulose reductase, xylitol dehydrogenase, xylulokinase and arabinitol dehydrogenase were induced in almost all time points (Additional file 20). Also of interest, we found that from the eight hydrophobins predicted in the $A$. niger genome [81], seven were found as being upregulated induced in SEB and the profile expression of one of them ( $h f b A$, An03g02400) was validated by RT-qPCR (Additional file 8). According to Schmoll et al. [71], T. reesei QM6a genome has 10 genes coding hydrophobins, we could identify nine of these in the genome of T. reesei RUT C30, and only two (125146 and 89290) were induced by SEB (Additional file 20). Hydrophobins are small fungal proteins $(\leq 20 \mathrm{kDa})$ able to adsorb the hydrophobic surfaces and mediate the interaction between the fungi and the medium through amphipathic layers [82]. They reduce the substrate surface tension in which the fungus is growing [82] and are involved in biofilm formation over the lignocellulosic biomass, as observed in A. nidulans grown on SEB [83]. Furthermore, hydrophobins are potential candidates for $T$. reesei and $A$. niger adhesion at the bagasse's cell wall.

Moreover, swollenin (swo1, 104220) and cip1 (121449), which also have role in biomass degradation $[84,85]$, showed high RPKM values and $\log _{2}$ (fold change) in $T$. reesei (Additional file 20), especially after $24 \mathrm{~h}$ of growth. The high expression of these genes was also validated by RT-qPCR (Additional file 9). It was demonstrated that swollenin can disrupt the cellulose structure by cleaving hydrogen bonds between the lignocellulose polysaccharides [86]. Swo1 displays endoglucanase activity being able to hydrolyze $\beta-1,4$ linkages in $\beta$-glucan and carboxymethylcellulose (CMC) [85]. It is not yet clear what the Cip1 function is, but this protein has a secretion signal and a CBM1 domain [87]. Cip1 presented an increasing 
expression along the time series ( $\log _{2}$ (fold change): $6 \mathrm{~h}$ : $3.86 ; 12 \mathrm{~h}: 6.24 ; 24 \mathrm{~h}: 9.26)$ and was also strongly induced in wheat straw [40] and sophorose [88]. In these two studies the expression of cip1 was similar to the profiles of endoglucanases and of the cellobiohydrolase cbh1, suggesting a potential of Cip1 in cellulose degradation. Interestingly, $A$. niger does not contain either of these genes, which reiterates the different strategies used by both fungi during biomass degradation.

Recently, a new class of enzymes called PADs (Prooxidant, Antioxidant, and Detoxification enzymes) has been drawing attention due to its putative participation in lignocellulose breakdown. PADs are detoxifying and lignin/phenol modification enzymes, such as catalase (CAT), superoxide dismutase (SOD), peroxidase, cytochrome P450 (p450), glutathione S-transferase (GST) and aldo-keto reductase (AKR). There are few papers in the literature relating the influence of these enzymes in the biomass saccharification and oxidative stress control [89-95]. We found that several genes coding for PADs were induced by SEB; in T. reesei, 1 CAT, 6 GSTs and 7 AKRs, while 2 CATs, 2 SODs, 10 GSTs, 4 peroxidases and 12 AKRs were induced in A. niger, some of them with high fold change values, such as An08g09150 and An07g00030 (Additional file 20). These enzymes could be acting on the oxidative control of the highly reactive ROS generated by the oxidative degradation driven by LPMOs (AA9) and other oxidative enzymes (AA3; AA6; AA7). And according to the high lignin proportion of steamexploded bagasse composition (34\%,), the peroxidases and aldo-keto reductases might be participating in the removal of lignin fraction, which can be as high as 34\% in SEB [96], enabling access to the cellulose by conventional GHs, as suggested previously [89, 97-99]. The role of these enzymes on biomass deconstruction is poorly explored in ascomycetes, but their upregulation in $T$. reesei RUT-C30 and $A$. niger N402 during the growth in SEB suggests that they can be acting (directly or indirectly) in this process.

Finally, we turn our attention to potentially new genes with important roles in biomass degradation. We focused on genes that have signal peptide cleavage sites, that could be secreted, and that have no reported function either at AspGD or JGI databases, and that do not have significant hits to protein domains. In A. niger, 146 genes were upregulated out of which 76 were induced in all time points (Additional file 21), some of them with high fold changes, being among the 20 most induced genes (Additional file 11). They showed an expression profile (Fig. 6) that is different from CAZymes (Fig. 4) and transporters (Fig. 5). In $T$. reesei, 66 genes of unknown function were identified as being upregulated, 25 of them in all growth conditions (Additional file 21). The high expression of these genes suggests that they can have a role on the saccharification metabolism, and are interesting targets for follow up studies.

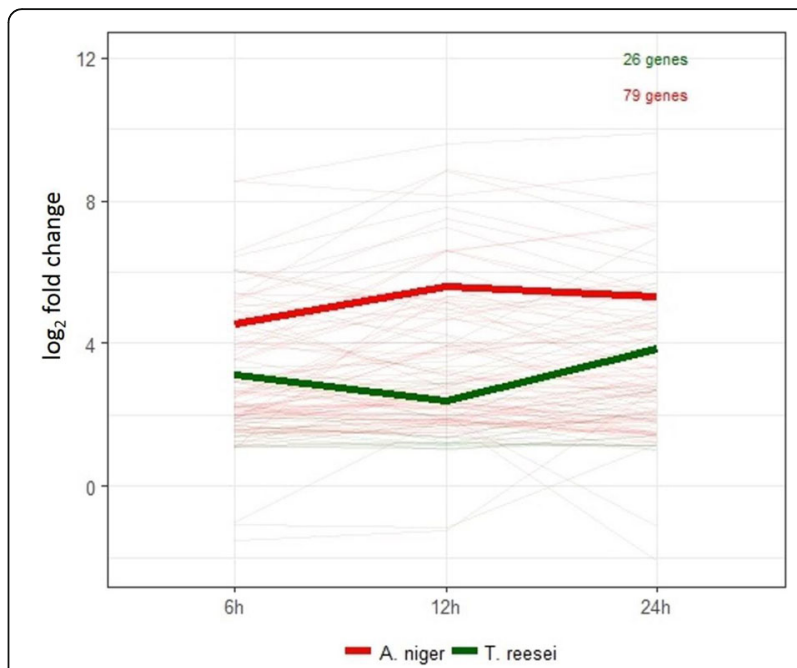

Fig. 6 Expression profile of genes coding unknown proteins with peptide signal predicted upregulated in A. niger N402 and T. reesei RUT-C30 transcriptomes. Thinner lines represent the individual gene expression ( $\log _{2}($ fold change)) for each fungus and the thicker ones the average of these values. Only genes upregulated in all time points $(6,12$ and $24 \mathrm{~h})$ were considered

\section{Conclusion}

This study describes a comparative transcriptome analysis of $T$. reesei RUT-C30 and A. niger N402 during growth on steam-exploded sugarcane bagasse as carbon source. A set of CAZymes, such as cellulases, hemicellulases and oxidative enzymes was expressed by both fungal strains, but their gene expression profiles was opposite to each other. During the time series evaluated in this work, T. reesei had an increasing activation of its CAZymes while A. niger had a faster transcriptional response, upregulating the most of them at $6 \mathrm{~h}$ and decreasing their transcription after that. Our findings revealed both strains upregulated several genes, which code for putative transporters of sugars and other small molecules, transcription factors, proteins of unknown functions and PAD enzymes. These proteins can be players in biomass degradation and deserve further studies to verify their role. Altogether, the data show that $A$. niger N402 and T. reesei RUT-C30 have differences in genes related to lignocellulose breakdown content and also in their expression profile. This knowledge can be exploited for the rational design of enzymatic cocktails and $2 \mathrm{G}$ ethanol production improvement.

\section{Methods}

Fungal strains and culture conditions

The fungi Trichoderma reesei RUT-C30 (ATCC 56765) and Aspergillus niger N402 (ATCC 64974) were kindly provided by Dr. Bernhard Seiboth and Dr. David Archer, respectively. As mentioned before, T. reesei RUT-C30 
strain was obtained after three random mutagenesis (with UV light and N-nitroguanidine) of the wild type QM6a [17]. A. niger N402 strain was produced in 1983 from N400 by two rounds of UV mutagenesis (personal communication, Dr Fons Debets, University of Wageningen). Both strains were kept in silica gel desiccant with $7 \%$ milk (w/v) at $4{ }^{\circ} \mathrm{C}$ [100]. Fungi were grown on basic culture medium (BCM) [44] with a predetermined concentration of carbon source according to our experimental conditions.

For cultivation in medium with SEB, the mycelia grown on the BCM were filtered, washed twice with sterile distilled water in order to eliminate any residual sugar and then transferred to fresh BCM deprived of $0.05 \%$ yeast extract but with $0.5 \%$ of SEB (w/v) as carbon source. SEB was treated as described by De Souza et al. [34], and exhaustively washed with deionized water until reducing sugars were not detected by DNS [101]. SEB was completely dry at $60^{\circ} \mathrm{C}$ for several days and sifted in a $600 \mu \mathrm{m}$ industrial sieve. Cellulose, hemicellulose and lignin proportion made up 47, 9 and $34 \%$ of the SEB, respectively [96]. All media were sterilized in an autoclave for $20 \mathrm{~min}$ at $121^{\circ} \mathrm{C}$ before using.

\section{Substrate-based induction conditions}

For RNA sequencing (RNA-seq) and quantitative reversetranscription PCR (RT-qPCR) experiments, T. reesei and $A$. niger spores were first cultivated in potato dextrose agar plate for 7-10 days at $29^{\circ} \mathrm{C}$ and $30^{\circ} \mathrm{C}$, respectively, and harvested by adding $1 \mathrm{~mL}$ of sterile distilled water. The spore suspensions were inoculated to a final concentration of 1 $\times 10^{6}$ spores per $30 \mathrm{~mL}$ of BCM culture in $250 \mathrm{~mL}$ flasks. T. reesei and $A$. niger spores were grown on BCM with $1 \%$ fructose $(\mathrm{w} / \mathrm{v})$ as the carbon source at $29^{\circ} \mathrm{C}$ and $30^{\circ} \mathrm{C}$, respectively, for 24 hours (h) (A. niger) or $48 \mathrm{~h}$ (T. reesei) in a rotary shaker with agitation of $200 \mathrm{rpm}$. After, the mycelia were transferred to $0.5 \% \mathrm{SEB}(\mathrm{w} / \mathrm{v})$ as the carbon source for 6, 12 and $24 \mathrm{~h}$, and to $1 \%$ fructose $(\mathrm{w} / \mathrm{v})$ for 24 $\mathrm{h}$ for the RNA-seq experiment and 6, 12 and $24 \mathrm{~h}$ for the RT-qPCR. The RNA-seq and RT-qPCR experiments were carried out in duplicate and triplicate, respectively. Fructose was used as control condition in all experiments because it is an inert sugar, which neither induces nor suppresses overall expression of lignocellulolytic enzymes [102]. For the growth of T. reesei, the cultures were maintained in constant light, as this influences positively cellulase gene expression [103]. Mycelia were harvested by filtration through Whatman grade 1 filters (GE Healthcare, Grandview Blvd. Waukesha, WI, USA), washed thoroughly with sterile water and immediately ground into powder in liquid nitrogen. Aliquots of $100 \mathrm{mg}$ ground mycelia were harvested and kept at $-80{ }^{\circ} \mathrm{C}$ until the RNA extraction.

\section{RNA extraction and RNA-seq}

Total RNA from aliquots was extracted using the RNeasy Plant Mini kit (Qiagen) according to manufacturer's instructions. RNA concentration was determined in a Nanodrop 2100c (Thermo Fisher Scientific, Waltham, MA, USA) and the integrity was evaluated in a 2100 Bioanalyzer (Agilent Technologies, Santa Clara, CA, USA) using the Agilent RNA 6000 Nano kit (Agilent Technologies, Santa Clara, CA, USA). Total RNA from two biological replicates per condition (SEB or fructose) from both fungi was used as input for the TruSeq RNA Sample Prep v2 kit (Illumina, San Diego, CA, USA) and the libraries were sequenced at the USC Epigenome Center (CA, USA) using the Illumina ${ }^{\oplus}$ HiSeq2000 system, producing single-end reads of $50 \mathrm{bp}$.

\section{RNA-seq analysis}

More than 30 million 50 bp single-end reads were obtained for both fungi after sequencing. First, these reads were size-filtered (minimum of $40 \mathrm{bp}$ ) and selected by quality $(Q>20)$ by AlienTrimmer software [104]. Filtered reads were mapped to the $T$. reesei RUT-C30 v1.0 genome available in the JGI Genome Portal $(9,852$ gene models, [105, 106]) and to A. niger CBS 513.88 genome from Aspergillus Genome Database AspGD (14,165 gene models, [62, 107]), using TopHat2 [108]. Saturation of exon-exon junctions at different subsampling fractions of the total number of reads was assessed to verify proper sequencing coverage, using RseQC [109]. Mapped reads were counted with the featureCounts function from the Rsubread v1.12.6 package [110] in R v3.0.2 [111]. Read counts were normalized using TMM [112]. Differentially expressed genes (DEGs) were identified with NOISeqBIO v2.8.0 [113] with the following parameters $\mathrm{k}=0.5$, nclust $=15, \mathrm{r}=20, \mathrm{lc}=1$, filter $=1, \mathrm{cpm}=1$; in order to minimize false positives and false negatives, the threshold value for significance $q$ $=0.95$ was used, which is equivalent to a FDR cutoff of 0.05 . Only DEGs with two-fold change cutoff (SEB versus fructose) were considered, i.e., $\log _{2}$-fold change $\geq 1$ (upregulated) or $\leq-1$ (downregulated). RPKM values were computed after TMM normalization for comparison and visualization of the transcriptional profiles of both fungi.

Further, upregulated genes were grouped into different categories according to functional information. CAZymes categories includes all GH, CE, PL, AA genes predicted by CAZy [53], but also available at the JGI and AspGD databases, only excluding the CE10 family that has been associated with non-carbohydrate substrates hydrolysis. Glycosyl transferases (GTs) were also removed from consideration as they work on fungal cell wall remodeling. Additionally, CAZymes and their annotations were retrieved from Benoit et al. [114] for A. niger and Häkkinen et al. [43] for $T$. reesei. Genes encoding CAZymes 
predicted by the dbCAN pipeline [115] (parameters: e-value < 1.00E-17; coverage > 0.45), but not found in JGI, AspGD database or in the previously mentioned publications, were included as well and labeled as putative CAZymes. Putative sugar transporter proteins (mainly, MFS and ABC transporters) were labeled as "transporters" and those related to ion, amino acids and drugs as "other transporters". The number of transmembrane helices was assessed by the TMHMM Server v2.0 [116]. Transcription factors were annotated following Pel et al. [62] and the Schmoll et al. [71] for A. niger and T. reesei, respectively. New candidate transcription factors were identified following the strategy proposed in Perez-Rodriguez et al. [117], with a set of updated classification rules (Renato Santos et al., unpublished results). For genes encoding proteins with no functional annotation in the JGI or AspGD databases, PFAM domains were searched using Motif Search tool [118]. The peptide signal was predicted by SignalP v4.1 [119] and it was considered as proteins of unknown function the ones containing PFAM domains with e-value $>1.00 \mathrm{E}-10$.

Gene Ontology (GO) annotation was obtained from JGI and AspGD and the enrichment analysis was performed with the Cytoscape's plugin BINGO 3.0.2, using the hypergeometric test and adjusting p-values for multiple testing with the Benjamini \& Hochberg's false discovery rate (FDR) method $(\mathrm{p} \leq 0.05)$. Orthologues between $T$. reesei and $A$. niger were predicted by applying the OrthoMCL pipeline [120]. Briefly, protein sequences were downloaded from JGI and AspGD databases, respectively. The all-vs-all BLAST similarity search was performed keeping hits with e-value $\leq 10^{-5}$. Orthologues identification groups was carried out with an inflation value of 1.5 (parameter of cluster tightness) [120] and a homology percent match threshold of $60 \%$.

\section{RT-qPCR analysis of selected genes}

After RNA-seq analysis, 9 DEGs from each fungal that were among the most upregulated genes, including CAZymes, transporters and other genes of interest were chosen for validation by RT-qPCR. Briefly, extracted RNA was treated with TURBO DNA-free kit (Applied Biosystems, Life Technologies) for depletion of any residual genomic DNA. SuperScript ${ }^{\mathrm{tm}}$ II Reverse Transcriptase (Invitrogen, Life Technologies) was used to synthesize cDNA from 400 ng of total RNA according to the manufacturer's instructions. Specific primers for each transcript were designed to amplify a fragment between $80 \mathrm{bp}$ and $150 \mathrm{bp}$ (Additional file 22), a first round of end-point PCR was performed with these primers and the products were separated by agarose gel electrophoresis and purified with PureLink Quick Gel Extraction kit (Invitrogen, Life Technologies). Purified PCR products were sequenced in $3500 x \mathrm{~L}$ Genetic
Analyzer (Applied Biosystems, Life Technologies), using BigDye $^{\bullet}$ Terminator v3.1 Cycle Sequencing (Applied Biosystems, Life Technologies) to confirm the amplicon sequences identity. The amplicons were subjected to a 10 -fold serial dilution (from $10^{-1}$ to $10^{-8}$ ) and used to construct a standard curve. Real-time PCR reactions were performed along with the five best points of the standard curve and the cDNA samples from the experiments (see above), to keep the same conditions for standards and experimental samples (relative standard curve method). The reactions were performed with 1.0 $\mu \mathrm{L}$ of $\mathrm{cDNA}$ or point dilution, $5.0 \mu \mathrm{L}$ of $\mathrm{SYBR}^{\circ}$ Green PCR Master Mix (Applied Biosystems, Life Technologies) and 2 pmol of each primer, in a final volume of 10 $\mu \mathrm{L}$. All RT-qPCR reactions were carried out in ViiA 7 Real Time PCR system (Applied Biosystems, Life Technologies) using the following amplification conditions: activation for 10 minutes at $95^{\circ} \mathrm{C}$ followed by 40 cycles of denaturation $\left(15\right.$ seconds at $\left.95^{\circ} \mathrm{C}\right)$, annealing and extension $\left(1\right.$ minute at $\left.60^{\circ} \mathrm{C}\right)$. Act and sarl genes were chosen for data normalization of $T$. reesei and A. niger gene expression, respectively [121, 122]. Only primer pairs with amplification efficiencies $\geq 85 \%$ and correlation coefficient $(\mathrm{r} 2) \geq 0.99$ were considered for analysis. Data acquisition and melting curve analysis were performed in ViiA RUO software (Applied Biosystems, Life Technologies).

\section{Additional files}

Additional file 1: Result of RNA sequencing for $A$. niger N402 and $T$. reesei RUT-C30 grown on sugarcane SEB and fructose. (XLSX $12 \mathrm{~kb}$ )

Additional file 2: All DEGs found in the transcriptomes of A. niger $\mathrm{N} 402$ and T. reesei RUT-C30 grown on sugarcane SEB. (XLSX 1286 kb)

Additional file 3: Gene ontology enrichment analysis. (XLSX 17 kb)

Additional file 4: Differentially expressed CAZymes upregulated in the A. niger N402 transcriptome. (XLSX $1000 \mathrm{~kb}$ )

Additional file 5: Differentially expressed CAZymes upregulated in the T. reesei RUT-C30 transcriptome. (XLSX $1074 \mathrm{~kb}$ )

Additional file 6: Predicted orthologues of genes coding CAZymes upregulated in both A. niger N402 and T. reesei RUT-C30 transcriptomes. (XLSX $14 \mathrm{~kb}$ )

Additional file 7: Transcriptional profile of main CAZy families related to lignocellulose degradation. (XLSX $444 \mathrm{~kb}$ )

Additional file 8: Validation of A. niger N402 RNA-seq data by RT-qPCR. (XLSX $355 \mathrm{~kb}$ )

Additional file 9: Validation of T. reesei RUT-C30 RNA-seq data by RT-qPCR. (XLSX $320 \mathrm{~kb}$ )

Additional file 10: Expression of the twenty most upregulated genes in T. reesei RUT-C30 transcriptome. (XLSX $26 \mathrm{~kb}$ )

Additional file 11: Expression of the twenty most upregulated genes in A. niger N402 transcriptome. (XLSX $30 \mathrm{~kb}$ )

Additional file 12: Putative new CAZymes of A. niger N402 and T. reesei RUT-C30 differentially expressed in their transcriptomes and identified by dbCAN. (XLSX 16 kb)

Additional file 13: Known and putative transporters upregulated in A. niger N402 transcriptome. (XLSX $41 \mathrm{~kb}$ ) 
Additional file 14: Known and putative transporters upregulated in $T$. reesei RUT-C30 transcriptome. (XLSX 26 kb)

Additional file 15: Predicted orthologue genes which code upregulated transporters in both A. niger N402 and T. reesei RUT-C30 transcriptomes. (XLSX $21 \mathrm{~kb})$

Additional file 16: Other putative upregulated transporters in both $A$. niger N402 and T. reesei RUT-C30 transcriptomes. (XLSX 196 kb)

Additional file 17: Known upregulated transcription factors in A. niger N402 transcriptome. (XLSX 36 kb)

Additional file 18: Known upregulated transcription factors in T. reesei RUT-C30 transcriptome. (XLSX 19 kb)

Additional file 19: Upregulated transcription factor-likes in both A. niger N402 and T. reesei RUT-C30 transcriptomes. (XLSX 20 kb)

Additional file 20: Interesting upregulated genes in A. niger N402 and T. reesei RUT-C30 transcriptomes. (XLSX $33 \mathrm{~kb}$ )

Additional file 21: Unknown proteins with predicted signal peptide whose genes were upregulated in A. niger N402 and T. reesei RUT-C30 transcriptomes. (XLSX $6133 \mathrm{~kb}$ )

Additional file 22: Primers used in the RT-qPCR analysis. (XLSX 13 kb)

\section{Acknowledgments}

The authors would like to thank Dr. João Paulo Lourenço Franco Cairo for the comments regarding the PAD enzymes, Dr. Charles Nicolet from USC Epigenome Center (CA, USA) for RNA sequencing support and all reviewers for their valuable comments.

\section{Funding}

This work received funding from Fundação de Amparo à Pesquisa do Estado de São Paulo (FAPESP, 2011/08945-9 and 2014/11766-7). GPB, CCS, ESS, RACS hold FAPESP scholarships (2015/08222-8, 2013/09541-4, 2014/11733-1, 2014/ 15799-7, respectively). GKZ and RMMTSD were granted scholarships from Coordenação de Aperfeiçoamento de Pessoal de Nível Superior (CAPES) and Conselho Nacional de Desenvolvimento Científico e Tecnológico (CNPq) scholarships, respectively.

\section{Availability of data and materials}

The data set supporting the results of this article is included within the article and its additional files. The raw data from $T$. reesei and A. niger RNAseq have been submitted to the National Center for Biotechnology Information (NCBI) in the BioProject under the accession numbers PRJNA350272 and PRJNA350271, respectively.

\section{Authors' contributions}

JVCO and GHG planned the experiments. GPB, CCS, GKZ, ATS performed the laboratory analyses. GPB, JVCO, ESS, AOP, RACS, RMMTSD, DMRP carried out the analysis of the data. JVCO, DMRP and GPB draft the manuscript. All authors have read and approved the final version of the manuscript.

\section{Competing interests}

The authors declare that they have no competing interests.

\section{Consent for publication}

Not applicable.

\section{Ethics approval and consent to participate} Not applicable.

\section{Publisher's Note}

Springer Nature remains neutral with regard to jurisdictional claims in published maps and institutional affiliations.

\section{Author details}

'Laboratório Nacional de Ciência e Tecnologia do Bioetanol (CTBE), Centro Nacional de Pesquisa em Energia e Materiais (CNPEM), Av Giuseppe Maximo Scolfaro 10000, Campinas, São Paulo Caixa Postal 6170, 13083-970, Brazil. ${ }^{2}$ Faculdade de Ciências Farmacêuticas de Ribeirão Preto, Universidade de São Paulo, Av do Café S/N, Ribeirão Preto, CEP, São Paulo 14040-903, Brazil.
${ }^{3}$ Current address: Laboratório de Biologia de Sistemas Regulatórios, Instituto de Química, Universidade de São Paulo, Av. Prof. Lineu Prestes, 748 - Butantã

- São Paulo - SP, São Paulo CEP 05508-000, Brazil.

Received: 22 December 2016 Accepted: 9 June 2017

Published online: 30 June 2017

\section{References}

1. Popp J, Harangi-Rakos M, Gabnai Z, Balogh P, Antal G, Bai A. Biofuels and their co-products as livestock feed: global economic and environmental implications. Molecules. 2016;21:285.

2. Canilha L, Chandel AK, Milessi TSS, Antunes FAF, Freitas WLC, Felipe MGA, et al. Bioconversion of sugarcane biomass into ethanol: an overview about composition, pretreatment methods, detoxification of hydrolysates, enzymatic saccharification, and ethanol fermentation. J Biomed Biotechnol. 2012;2012

3. Della-Bianca BE, Basso TO, Stambuk BU, Basso LC, Gombert AK. What do we know about the yeast strains from the Brazilian fuel ethanol industry? Appl Microbiol Biotechnol. 2013;97:979-91.

4. Amorim HV, Lopes ML, Oliveira JVC, Buckeridge MS, Goldman GH. Scientific challenges of bioethanol production in Brazil. Appl Microbiol Biotechnol. 2011;91:1267-75.

5. Rabelo SC, Carrere H, Filho RM, Costa AC. Production of bioethanol, methane and heat from sugarcane bagasse in a biorefinery concept. Bioresour Technol. 2011:102:7887-95.

6. Leite RCC, Leal MRLV, Cortez LAB, Griffin WM, Scandiffio MIG. Can Brazil replace $5 \%$ of the 2025 gasoline world demand with ethanol? Energy. 2009;34:655-61.

7. Clark JH, Luque R, Matharu AS. Green chemistry, biofuels, and biorefinery. Annu Rev Chem Biomol Eng. 2012;3:183-207.

8. Kricka W, Fitzpatrick J, Bond U. Challenges for the production of bioethanol from biomass using recombinant yeasts. Adv Appl Microbiol. 2015;92:89-125.

9. Klein-Marcuschamer D, Oleskowicz-Popiel P, Simmons BA, Blanch HW. The challenge of enzyme cost in the production of lignocellulosic biofuels. Biotechnol Bioeng. 2012;109:1083-7.

10. Singhania RR. Production of Celluloytic Enzymes for the Hydrolysis of Lignocellulosic Biomass. In: Singhania RR, editor. Biofuels: Alternative Feedstocks and Conversion Processes. Amsterdam: Elsevier; 2011. p. 101-22.

11. Mohanram S, Amat D, Choudhary J, Arora A, Nain L. Novel perspectives for evolving enzyme cocktails for lignocellulose hydrolysis in biorefineries. Sustainable Chemical Processes. 2013;1:15.

12. Prieto $M$, Wedin $M$. Dating the diversification of the major lineages of Ascomycota (Fungi). PLoS One. 2013;8:e65576.

13. Mandels M, Reese ET. Induction of cellulase in Trichoderma viride as influenced by carbon sources and metals. J Bacteriol. 1957;73:269-78.

14. IImen M, Thrane C, Penttila M. The glucose repressor gene cre 1 of Trichoderma: isolation and expression of a full-length and a truncated mutant form. Mol Gen Genet. 1996;251:451-60.

15. Seidl V, Gamauf C, Druzhinina IS, Seiboth B, Hartl L, Kubicek CP. The Hypocrea jecorina (Trichoderma reesei) hypercellulolytic mutant RUT C30 lacks a $85 \mathrm{~kb}$ (29 gene-encoding) region of the wild-type genome. BMC Genomics. 2008;9:327.

16. Schuster A, Schmoll M. Biology and biotechnology of Trichoderma. App Microbiol Biotechnol. 2010:87:787-99.

17. Peterson R, Nevalainen H. Trichoderma reesei RUT-C30-thirty years of strain improvement. Microbiology. 2012;158:58-68.

18. Baker SE. Aspergillus niger genomics: past, present and into the future. Med Mycol. 2006:44(Suppl 1):S17-21

19. Lu F, Pinga K, Wena L, Zhaob W, Wanga Z, Chua J, et al. Enhancing gluconic acid production by controlling the morphology of Aspergillus niger in submerged fermentation. Process Biochemistry. 2015;50:1342-8.

20. Rasoulnia P, Mousavi SM. Maximization of organic acids production by Aspergillus niger in a bubble column bioreactor for $\mathrm{V}$ and Ni recovery enhancement from power plant residual ash in spent-medium bioleaching experiments. Bioresour Technol. 2016:216:729-36.

21. Mitidieri S, Souza Martinelli AH, Schrank A, Vainstein MH. Enzymatic detergent formulation containing amylase from Aspergillus niger: a comparative study with commercial detergent formulations. Bioresour Technol. 2006;97:1217-24.

22. Patil SR, Dayanand A. Optimization of process for the production of fungal pectinases from deseeded sunflower head in submerged and solid-state conditions. Bioresour Technol. 2006;97:2340-4. 
23. Esawy MA, Gamal AA, Kamel Z, Ismail AM, Abdel-Fattah AF. Evaluation of free and immobilized Aspergillus niger NRC1ami pectinase applicable in industrial processes. Carbohydr Polym. 2013;92:1463-9.

24. Rocha NRAF, Barros MA, Fischer J, Filho UC, Cardoso VL. Ethanol production from agroindustrial biomass using a crude enzyme complex produced by Aspergillus niger. Renewable Energy. 2013;57:432-5.

25. van Dijck PW, Selten GC, Hempenius RA. On the safety of a new generation of DSM Aspergillus niger enzyme production strains. Regul Toxicol Pharmacol. 2003;38:27-35.

26. Ruijter GJ, Visser J. Carbon repression in Aspergilli. FEMS Microbiol Lett. 1997;151:103-14.

27. Aro N, Pakula T, Penttila M. Transcriptional regulation of plant cell wall degradation by filamentous fungi. FEMS Microbiol Rev. 2005;29:719-39.

28. Stricker AR, Mach RL, de Graaff LH. Regulation of transcription of cellulasesand hemicellulases-encoding genes in Aspergillus niger and Hypocrea jecorina (Trichoderma reesei). Appl Microbiol Biotechnol. 2008;78:211-20.

29. Kowalczyk JE, Benoit I, de Vries RP. Regulation of plant biomass utilization in Aspergillus. Adv Appl Microbiol. 2014;88:31-56.

30. Lombard V, Golaconda Ramulu H, Drula E, Coutinho PM, Henrissat B. The carbohydrate-active enzymes database (CAZy) in 2013. Nucleic Acids Res. 2014;42:D490-5.

31. Pullan ST, Daly P, Delmas S, Ibbett R, Kokolski M, Neiteler A, et al. RNAsequencing reveals the complexities of the transcriptional response to lignocellulosic biofuel substrates in Aspergillus niger. Fungal Biol Biotechnol. 2014;1:1-14.

32. Delmas S, Pullan ST, Gaddipati S, Kokolski M, Malla S, Blythe MJ, et al. Uncovering the genome-wide transcriptional responses of the filamentous fungus Aspergillus niger to lignocellulose using RNA sequencing. PLoS Genet. 2012;8:1-13.

33. van Munster JM, Daly P, Delmas S, Pullan ST, Blythe MJ, Malla S, et al. The role of carbon starvation in the induction of enzymes that degrade plantderived carbohydrates in Aspergillus niger. Fungal Genet Biol. 2014;72:34-47.

34. de Souza WR, de Gouvea PF, Savoldi M, Malavazi I, de Souza Bernardes LA, Goldman $\mathrm{MH}$, et al. Transcriptome analysis of Aspergillus niger grown on sugarcane bagasse. Biotechnol Biofuels. 2011;4:40.

35. Jorgensen TR, Goosen T, Hondel CA, Ram AF, Iversen JJ. Transcriptomic comparison of Aspergillus niger growing on two different sugars reveals coordinated regulation of the secretory pathway. BMC Genomics. 2009;10:1-16.

36. Andersen MR, Vongsangnak W, Panagiotou G, Salazar MP, Lehmann L, Nielsen J. A trispecies Aspergillus microarray: comparative transcriptomics of three Aspergillus species. Proc Natl Acad Sci U S A. 2008;105:4387-92.

37. Coutinho PM, Andersen MR, Kolenova K, vanKuyk PA, Benoit I, Gruben BS, Trejo-Aguilar B, Visser $H$, van Solingen P, Pakula T, et al. Post-genomic insights into the plant polysaccharide degradation potential of Aspergillus nidulans and comparison to Aspergillus niger and Aspergillus oryzae. Fungal Genet Biol. 2009;46 Suppl 1:S161-S169.

38. Nitsche BM, Jorgensen TR, Akeroyd M, Meyer V, Ram AF. The carbon starvation response of Aspergillus niger during submerged cultivation: insights from the transcriptome and secretome. BMC Genomics. 2012;13:380

39. de Souza WR, Maitan-Alfenas GP, de Gouvea PF, Brown NA, Savoldi M, Battaglia $\mathrm{E}$, et al. The influence of Aspergillus niger transcription factors AraR and $X \ln R$ in the gene expression during growth in D-xylose, L-arabinose and steam-exploded sugarcane bagasse. Fungal Genet Biol. 2013;60:29-45.

40. Ries L, Pullan ST, Delmas S, Malla S, Blythe MJ, Archer DB. Genome-wide transcriptional response of Trichoderma reesei to lignocellulose using RNA sequencing and comparison with Aspergillus niger. BMC Genomics. 2013;14:541.

41. Bischof R, Fourtis L, Limbeck A, Gamauf C, Seiboth B, Kubicek CP. Comparative analysis of the Trichoderma reesei transcriptome during growth on the cellulase inducing substrates wheat straw and lactose. Biotechnol Biofuels. 2013:6:127.

42. dos Santos CL, Pedersoli W, Antoniêto A, Steindorff A, Silva-Rocha R, Martinez-Rossi N, et al. Comparative metabolism of cellulose, sophorose and glucose in Trichoderma reesei using high-throughput genomic and proteomic analyses. Biotechnol Biofuels. 2014;7:41.

43. Hakkinen M, Arvas M, Oja M, Aro N, Penttila M, Saloheimo M, et al. Reannotation of the CAZy genes of Trichoderma reesei and transcription in the presence of lignocellulosic substrates. Microb Cell Fact. 2012;11:1-11.

44. Borin GP, Sanchez CC, de Souza AP, de Santana ES, de Souza AT, Paes Leme AF, et al. Comparative secretome analysis of Trichoderma reesei and Aspergillus niger during growth on sugarcane biomass. PLoS One. 2015;10:e0129275.
45. Florencio C, Cunha FM, Badino AC, Farinas CS, Ximenes E, Ladisch MR. Secretome analysis of Trichoderma reesei and Aspergillus niger cultivated by submerged and sequential fermentation processes: Enzyme production for sugarcane bagasse hydrolysis. Enzyme Microb Technol. 2016;90:53-60.

46. Zhang W, Kou Y, Xu J, Cao Y, Zhao G, Shao J, et al. Two major facilitator superfamily sugar transporters from Trichoderma reesei and their roles in induction of cellulase biosynthesis. J Biol Chem. 2013;288:32861-72.

47. Huang ZB, Chen XZ, Qin LN, Wu HQ, Su XY, Dong ZY. A novel major facilitator transporter TrSTR1 is essential for pentose utilization and involved in xylanase induction in Trichoderma reesei. Biochem Biophys Res Commun. 2015;460:663-9.

48. Jacquet N, Maniet G, Vanderghem C, Delvigne F, Richel A. Application of Steam Explosion as Pretreatment on Lignocellulosic Material: A Review. Ind Eng Chem Res. 2015;54:2593-8.

49. Zhao S, Fung-Leung WP, Bittner A, Ngo K, Liu X. Comparison of RNASeq and microarray in transcriptome profiling of activated $T$ cells. PLoS One. 2014;9:e78644

50. Poggi-Parodi D, Bidard F, Pirayre A, Portnoy T, Blugeon C, Seiboth B, et al. Kinetic transcriptome analysis reveals an essentially intact induction system in a cellulase hyper-producer Trichoderma reesei strain. Biotechnol Biofuels. 2014;7:173.

51. Segato F, Damasio AR, de Lucas RC, Squina FM, Prade RA. Genomics review of holocellulose deconstruction by aspergilli. Microbiol Mol Biol Rev. 2014;78:588-613.

52. Hemsworth GR, Johnston EM, Davies GJ, Walton PH. Lytic Polysaccharide Monooxygenases in Biomass Conversion. Trends Biotechnol. 2015;33:747-61.

53. Levasseur A, Drula E, Lombard V, Coutinho PM, Henrissat B. Expansion of the enzymatic repertoire of the CAZy database to integrate auxiliary redox enzymes. Biotechnol Biofuels. 2013;6:41.

54. Saloheimo M, Nakari-Setala T, Tenkanen M, Penttila M. cDNA cloning of a Trichoderma reesei cellulase and demonstration of endoglucanase activity by expression in yeast. Eur J Biochem. 1997;249:584-91.

55. Karlsson J, Saloheimo M, Siika-Aho M, Tenkanen M, Penttila M, Tjerneld F. Homologous expression and characterization of Cel61A (EG IV) of Trichoderma reesei. Eur J Biochem. 2001;268:6498-507.

56. Tanghe M, Danneels B, Camattari A, Glieder A, Vandenberghe I, Devreese $B$, et al. Recombinant expression of Trichoderma reesei Cel61 A in Pichia pastoris: optimizing yield and $\mathrm{N}$-terminal processing. Mol Biotechnol. 2015;57:1010-7.

57. Frederick KR, Tung J, Emerick RS, Masiarz FR, Chamberlain SH, Vasavada A, et al. Glucose oxidase from Aspergillus niger. Cloning, gene sequence, secretion from Saccharomyces cerevisiae and kinetic analysis of a yeast-derived enzyme. J Biol Chem. 1990;265:3793-802.

58. Hatzinikolaou DG, Hansen OC, Macris BJ, Tingey A, Kekos D, Goodenough P, et al. A new glucose oxidase from Aspergillus niger: characterization and regulation studies of enzyme and gene. Appl Microbiol Biotechnol. 1996;46:371-81.

59. Kommoju PR, Chen ZW, Bruckner RC, Mathews FS, Jorns MS. Probing oxygen activation sites in two flavoprotein oxidases using chloride as an oxygen surrogate. Biochemistry. 2011;50:5521-34.

60. Kracher D, Scheiblbrandner S, Felice AK, BresImayr E, Preims M, Ludwicka K, et al. Extracellular electron transfer systems fuel cellulose oxidative degradation. Science. 2016;352:1098-101.

61. Carro J, Serrano S, Ferreira P, Martínez AT. Fungal Aryl-Alcohol Oxidase in Lignocellulose Degradation and Bioconversion. In: Carro J, Serrano S, Ferreira P, Martínez AT, editors. Microbial Enzymes in Bioconversions of Biomass. Springer International Publishing; 2016.

62. Pel HJ, de Winde JH, Archer DB, Dyer PS, Hofmann G, Schaap PJ, et al. Genome sequencing and analysis of the versatile cell factory Aspergillus niger CBS 513.88. Nat Biotechnol. 2007;25:221-31.

63. Wang X, Zhang X, Liu L, Xiang M, Wang W, Sun X, et al. Genomic and transcriptomic analysis of the endophytic fungus Pestalotiopsis fici reveals its lifestyle and high potential for synthesis of natural products. BMC Genomics. 2015;16:28.

64. Dos Santos $C L$, de Paula RG, Antonieto AC, Persinoti GF, Silva-Rocha R, Silva RN. Understanding the Role of the Master Regulator XYR1 in Trichoderma reesei by Global Transcriptional Analysis. Front Microbiol. 2016;7:175.

65. Young EM, Comer AD, Huang H, Alper HS. A molecular transporter engineering approach to improving xylose catabolism in Saccharomyces cerevisiae. Metab Eng. 2012;14:401-11.

66. Zhang B, Zhang J, Wang D, Han R, Ding R, Gao X, et al. Simultaneous fermentation of glucose and xylose at elevated temperatures co-produces 
ethanol and xylitol through overexpression of a xylose-specific transporter in engineered Kluyveromyces marxianus. Bioresour Technol. 2016;216:227-37.

67. Sloothaak J, Tamayo-Ramos JA, Odoni DI, Laothanachareon T, Derntl C, Mach-Aigner AR, et al. Identification and functional characterization of novel xylose transporters from the cell factories Aspergillus niger and Trichoderma reesei. Biotechnol Biofuels. 2016;9:148.

68. Ivanova C, Baath JA, Seiboth B, Kubicek CP. Systems analysis of lactose metabolism in Trichoderma reesei identifies a lactose permease that is essential for cellulase induction. PLoS One. 2013;8:e62631.

69. Saloheimo A, Rauta J, Stasyk OV, Sibirny AA, Penttila M, Ruohonen L. Xylose transport studies with xylose-utilizing Saccharomyces cerevisiae strains expressing heterologous and homologous permeases. Appl Microbiol Biotechnol. 2007;74:1041-52.

70. Hammel KE, Kapich AN, Jensen KA, Ryan ZC. Reactive oxygen species as agents of wood decay by fungi. Enzyme and Microb Technol. 2002;30:45-453.

71. Schmoll M, Dattenbock C, Carreras-Villasenor N, Mendoza-Mendoza A, Tisch D, Aleman Ml, et al. The Genomes of Three Uneven Siblings: Footprints of the Lifestyles of Three Trichoderma Species. Microbiol Mol Biol Rev. 2016;80:205-327.

72. Kowalczyk JE, Gruben BS, Battaglia E, Wiebenga A, Majoor E, de Vries RP. Genetic Interaction of Aspergillus nidulans gal $\mathrm{R}, \mathrm{x} \mid \mathrm{nR}$ and araR in Regulating D-Galactose and L-Arabinose Release and Catabolism Gene Expression. PLoS One. 2015;10:e0143200.

73. Suzuki K, Tanaka M, Konno Y, Ichikawa T, Ichinose S, Hasegawa-Shiro S, et al. Distinct mechanism of activation of two transcription factors, AmyR and MalR, involved in amylolytic enzyme production in Aspergillus oryzae. Appl Microbiol Biotechnol. 2015;99:1805-15.

74. Glassop D, Roessner U, Bacic A, Bonnett GD. Changes in the sugarcane metabolome with stem development. Are they related to sucrose accumulation? Plant Cell Physiol. 2007;48:573-84

75. De Souza AP, Leite DCC, Pattathil S, Hahn MG, Buckeridge MS. Composition and Structure of Sugarcane Cell Wall Polysaccharides: Implications for Second-Generation Bioethanol Production. Bioenerg Res. 2013:1-16.

76. Martens-Uzunova ES, Schaap PJ. Assessment of the pectin degrading enzyme network of Aspergillus niger by functional genomics. Fungal Genet Biol. 2009;46(Suppl 1):S170-9.

77. Gruben BS, Zhou M, Wiebenga A, Ballering J, Overkamp KM, Punt PJ, et al. Aspergillus niger RhaR, a regulator involved in L-rhamnose release and catabolism. Appl Microbiol Biotechnol. 2014;98:5531-40.

78. de Vries RP, Visser J, de Graaff LH. CreA modulates the XInR-induced expression on xylose of Aspergillus niger genes involved in xylan degradation. Res Microbiol. 1999;150:281-5.

79. Drysdale MR, Kolze SE, Kelly JM. The Aspergillus niger carbon catabolite repressor encoding gene, creA. Gene. 1993;130:241-5.

80. Yuan XL, van der Kaaij RM, van den Hondel CA, Punt PJ, van der Maarel MJ, Dijkhuizen L, et al. Aspergillus niger genome-wide analysis reveals a large number of novel alpha-glucan acting enzymes with unexpected expression profiles. Mol Genet Genomics. 2008;279:545-61.

81. Jensen BG, Andersen MR, Pedersen MH, Frisvad JC, Sondergaard I. Hydrophobins from Aspergillus species cannot be clearly divided into two classes. BMC Res Notes. 2010;3:344.

82. Bayry J, Aimanianda V, Guijarro JI, Sunde M, Latge JP. Hydrophobins-unique fungal proteins. PLoS Pathog. 2012;8:e1002700.

83. Brown NA, Ries LN, Reis TF, Rajendran R, Correa Dos Santos RA, Ramage G, et al. RNAseq reveals hydrophobins that are involved in the adaptation of Aspergillus nidulans to lignocellulose. Biotechnol Biofuels. 2016;9:145.

84. Eibinger M, Sigl K, Sattelkow J, Ganner T, Ramoni J, Seiboth B, et al. Functional characterization of the native swollenin from Trichoderma reesei: study of its possible role as C1 factor of enzymatic lignocellulose conversion. Biotechnol Biofuels. 2016;9:178.

85. Kubicek CP, Kubicek EM. Enzymatic deconstruction of plant biomass by fungal enzymes. Curr Opin Chem Biol. 2016;35:51-7.

86. Verma D, Jin S, Kanagaraj A, Singh ND, Daniel J, Kolattukudy PE, et al. Expression of fungal cutinase and swollenin in tobacco chloroplasts reveals novel enzyme functions and/or substrates. PLoS One. 2013;8:e57187.

87. Lehmann L, Ronnest NP, Jorgensen $\mathrm{Cl}$, Olsson L, Stocks SM, Jorgensen HS, et al. Linking hydrolysis performance to Trichoderma reesei cellulolytic enzyme profile. Biotechnol Bioeng. 2016;113:1001-10.

88. Foreman PK, Brown D, Dankmeyer L, Dean R, Diener S, Dunn-Coleman NS, et al. Transcriptional regulation of biomass-degrading enzymes in the filamentous fungus Trichoderma reesei. J Biol Chem. 2003;278:31988-97.
89. Sethi A, Slack JM, Kovaleva ES, Buchman GW, Scharf ME. Lignin-associated metagene expression in a lignocellulose-digesting termite. Insect Biochem Mol Biol. 2013;43:91-101.

90. Franco Cairo JP, Carazzolle MF, Leonardo FC, Mofatto LS, Brenelli LB, Goncalves TA, et al. Expanding the knowledge on lignocellulolytic and redox enzymes of worker and soldier castes from the lower termite Coptotermes gestroi. Front Microbiol. 2016;7:1518.

91. Rashid GM, Taylor CR, Liu Y, Zhang X, Rea D, Fulop V, et al. Identification of manganese superoxide dismutase from Sphingobacterium sp. T2 as a novel bacterial enzyme for lignin oxidation. ACS Chem Biol. 2015;10:2286-94.

92. Mathieu Y, Prosper P, Buee M, Dumarcay S, Favier F, Gelhaye E, et al. Characterization of a Phanerochaete chrysosporium glutathione transferase reveals a novel structural and functional class with ligandin properties. J Biol Chem. 2012;287:39001-11.

93. Zhang J, Presley GN, Hammel KE, Ryu JS, Menke JR, Figueroa M, et al. Localizing gene regulation reveals a staggered wood decay mechanism for the brown rot fungus Postia placenta. Proc Natl Acad Sci U S A. 2016;113:10968-73.

94. Bourdais A, Bidard F, Zickler D, Berteaux-Lecellier V, Silar P, Espagne E. Wood utilization is dependent on catalase activities in the filamentous fungus Podospora anserina. PLoS One. 2012;7:e29820.

95. Scott BR, Huang HZ, Frickman J, Halvorsen R, Johansen KS. Catalase improves saccharification of lignocellulose by reducing lytic polysaccharide monooxygenase-associated enzyme inactivation. Biotechnol Lett. 2016;38:425-34

96. Wanderley MC, Martin C, Rocha GJ, Gouveia ER. Increase in ethanol production from sugarcane bagasse based on combined pretreatments and fed-batch enzymatic hydrolysis. Bioresour Technol. 2013;128:448-53.

97. Fernandez-Fueyo E, Ruiz-Duenas FJ, Martinez AT. Engineering a fungal peroxidase that degrades lignin at very acidic pH. Biotechnol Biofuels. 2014;7:114

98. Correa RC, da Silva BP, Castoldi R, Kato CG, de Sa-Nakanishi AB, Peralta RA, et al. Spent mushroom substrate of Pleurotus pulmonarius: a source of easily hydrolyzable lignocellulose. Folia Microbiol (Praha). 2016;61:439-48.

99. Kuuskeri J, Hakkinen M, Laine P, Smolander OP, Tamene F, Miettinen S, et al. Time-scale dynamics of proteome and transcriptome of the white-rot fungus Phlebia radiata: growth on spruce wood and decay effect on lignocellulose. Biotechnol Biofuels. 2016;9:192.

100. Nakasone KK, Peterson SW, Jong SC. Preservation and distribution of fungal cultures. In: Nakasone KK, Peterson SW, Jong SC, editors. Biodiversity of Fungi: Inventory and Monitoring Methods. Amsterdam: Elsevier Academic Press; 2004. p. 37-47.

101. Miller GL. Use of dinitrosalicylic acid reagent for determination of reducing sugar. Anal Chem. 1959;31:426-8.

102. Amore A, Giacobbe S, Faraco V. Regulation of cellulase and hemicellulase gene expression in fungi. Curr Genomics. 2013;14:230-49.

103. Schmoll M, Franchi L, Kubicek CP. Envoy, a PAS/LOV domain protein of Hypocrea jecorina (Anamorph Trichoderma reesei), modulates cellulase gene transcription in response to light. Eukaryot Cell. 2005;4:1998-2007.

104. Criscuolo A, Brisse S. AlienTrimmer: a tool to quickly and accurately trim off multiple short contaminant sequences from high-throughput sequencing reads. Genomics. 2013;102:500-6.

105. Nordberg H, Cantor M, Dusheyko S, Hua S, Poliakov A, Shabalov I, et al. The genome portal of the Department of Energy Joint Genome Institute: 2014 updates. Nucleic Acids Res. 2014;42:D26-31.

106. Le Crom S, Schackwitz W, Pennacchio L, Magnuson JK, Culley DE, Collett JR, et al. Tracking the roots of cellulase hyperproduction by the fungus Trichoderma reesei using massively parallel DNA sequencing. Proc Natl Acad Sci U S A. 2009;106:16151-6.

107. Cerqueira GC, Arnaud MB, Inglis DO, Skrzypek MS, Binkley G, Simison M, et al. The Aspergillus Genome Database: multispecies curation and incorporation of RNA-Seq data to improve structural gene annotations. Nucleic Acids Res. 2014;42:D705-10.

108. Kim D, Pertea G, Trapnell C, Pimentel H, Kelley R, Salzberg SL. TopHat2: accurate alignment of transcriptomes in the presence of insertions, deletions and gene fusions. Genome Biol. 2013;14:R36.

109. Wang L, Wang S, Li W. RSeQC: quality control of RNA-seq experiments. Bioinformatics. 2012;28:2184-5.

110. Liao Y, Smyth GK, Shi W. featureCounts: an efficient general purpose program for assigning sequence reads to genomic features. Bioinformatics. 2014;30:923-30.

111. R Development Core Team. R: A language and environment for statistical computing. Vienna, Austria. URL http://www.R-project.org/:: R Foundation for Statistical Computing; 2015. 
112. Robinson MD, Oshlack A. A scaling normalization method for differential expression analysis of RNA-seq data. Genome Biol. 2010;11:R25.

113. Tarazona S, Garcia-Alcalde F, Dopazo J, Ferrer A, Conesa A. Differential expression in RNA-seq: a matter of depth. Genome Res. 2011;21:2213-23.

114. Benoit I, Culleton H, Zhou M, DiFalco M, Aguilar-Osorio G, Battaglia E, et al. Closely related fungi employ diverse enzymatic strategies to degrade plant biomass. Biotechnol Biofuels. 2015;8:107.

115. Yin Y, Mao X, Yang J. Chen X, Mao F. Xu Y. dbCAN: a web resource for automated carbohydrate-active enzyme annotation. Nucleic Acids Res. 2012;40:W445-51.

116. Sonnhammer EL, von Heijne G, Krogh A. A hidden Markov model for predicting transmembrane helices in protein sequences. Proc Int Conf Intell Syst Mol Biol. 1998;6:175-82.

117. Perez-Rodriguez P, Riano-Pachon DM, Correa LG, Rensing SA, Kersten B, Mueller-Roeber B. PInTFDB: updated content and new features of the plant transcription factor database. Nucleic Acids Res. 2010;38:D822-7.

118. Motif Search 2016. http://www.genome.jp/tools/motif/. Accessed Mar 2016.

119. Petersen TN, Brunak S, von Heijne G, Nielsen H. SignalP 4.0: discriminating signal peptides from transmembrane regions. Nat Methods. 2011;8:785-6.

120. Li L, Stoeckert CJ Jr, Roos DS. OrthoMCL: identification of ortholog groups for eukaryotic genomes. Genome Res. 2003;13:2178-89.

121. Steiger MG, Mach RL, Mach-Aigner AR. An accurate normalization strategy for RT-qPCR in Hypocrea jecorina (Trichoderma reesei). J Biotechnol. 2010;145:30-7.

122. Bohle K, Jungebloud A, Gocke Y, Dalpiaz A, Cordes C, Horn H, et al. Selection of reference genes for normalisation of specific gene quantiifcation data of Aspergillus niger. J Biotechnol. 2007;132:353-8.

123. van Peij NN, Visser J, de Graaff LH. Isolation and analysis of $x \ln R$, encoding a transcriptional activator co-ordinating xylanolytic expression in Aspergillus niger. Mol Microbiol. 1998;27:131-42.

124. Stricker AR, Grosstessner-Hain K, Wurleitner E, Mach RL. Xyr1 (xylanase regulator 1 ) regulates both the hydrolytic enzyme system and D-xylose metabolism in Hypocrea jecorina. Eukaryot Cell. 2006:5:2128-37.

125. Dowzer CE, Kelly JM. Analysis of the creA gene, a regulator of carbon catabolite repression in Aspergillus nidulans. Mol Cell Biol. 1991;11:5701-9.

126. Strauss J, Mach RL, Zeilinger S, Hartler G, Stoffler G, Wolschek M, et al. Cre1, the carbon catabolite repressor protein from Trichoderma reesei. FEBS Lett. 1995;376:103-7.

127. Battaglia E, Visser L, Nijssen A, van Veluw GJ, Wosten HA, de Vries RP. Analysis of regulation of pentose utilisation in Aspergillus niger reveals evolutionary adaptations in Eurotiales. Stud Mycol. 2011;69:31-8.

128. van Kuyk PA, Benen JA, Wosten HA, Visser J, de Vries RP. A broader role for AmyR in Aspergillus niger: regulation of the utilisation of D-glucose or D-galactose containing oligo- and polysaccharides. Appl Microbiol Biotechnol. 2012;93:285-93.

129. Aro N, Ilmén M, Saloheimo A, Penttilä M. ACEl of Trichoderma reesei is a repressor of cellulase and xylanase expression. Appl environ microbiol. 2003;69:56-65.

130. Aro N, Saloheimo A, IImen M, Penttila M. ACEll, a novel transcriptional activator involved in regulation of cellulase and xylanase genes of Trichoderma reesei. J Biol Chem. 2001;276:24309-14.

131. Hakkinen M, Valkonen MJ, Westerholm-Parvinen A, Aro N, Arvas M, Vitikainen $\mathrm{M}$, et al. Screening of candidate regulators for cellulase and hemicellulase production in Trichoderma reesei and identification of a factor essential for cellulase production. Biotechnol Biofuels. 2014;7:14

132. Nitta M, Furukawa T, Shida Y, Mori K, Kuhara S, Morikawa Y, et al. A new Zn(II)(2)Cys(6)-type transcription factor BgIR regulates beta-glucosidase expression in Trichoderma reesei. Fungal Genet Biol. 2012;49:388-97.

133. Tani S, Kawaguchi T, Kobayashi T. Complex regulation of hydrolytic enzyme genes for cellulosic biomass degradation in filamentous fungi. Appl Microbiol Biotechnol. 2014;98:4829-37.

134. Ogawa M, Kobayashi T, Koyama Y. ManR, a transcriptional regulator of the beta-mannan utilization system, controls the cellulose utilization system in Aspergillus oryzae. Biosci Biotechnol Biochem. 2013;77:426-9.

135. Gruben BS, Zhou M, de Vries RP. GalX regulates the D-galactose oxidoreductive pathway in Aspergillus niger. FEBS Lett. 2012;586:3980-5.

136. Zeilinger S, Ebner A, Marosits T, Mach R, Kubicek CP. The Hypocrea jecorina HAP 2/3/5 protein complex binds to the inverted CCAAT-box (ATTGG) within the cbh2 (cellobiohydrolase Il-gene) activating element. Mol Genet Genomics. 2001;266:56-63.

137. Derntl C, Rassinger A, Srebotnik E, Mach RL, Mach-Aigner AR. Xpp1 regulates the expression of xylanases, but not of cellulases in Trichoderma reesei. Biotechnol Biofuels. 2015;8:112.
138. Kappel L, Gaderer R, Flipphi M, Seidl-Seiboth V. The N-acetylglucosamine catabolic gene cluster in Trichoderma reesei is controlled by the Ndt80-like transcription factor RON1. Mol Microbiol. 2016;99:640-57.

139. Kunitake E, Tani S, Sumitani J, Kawaguchi T. A novel transcriptional regulator, ClbR, controls the cellobiose- and cellulose-responsive induction of cellulase and xylanase genes regulated by two distinct signaling pathways in Aspergillus aculeatus. Appl Microbiol Biotechnol. 2013;97:2017-28.

140. He R, Ma L, Li C, Jia W, Li D, Zhang D, et al. Trpac1, a pH response transcription regulator, is involved in cellulase gene expression in Trichoderma reesei. Enzyme Microb Technol. 2014;67:17-26.

141. Kunitake E, Hagiwara D, Miyamoto K, Kanamaru K, Kimura M, Kobayashi T. Regulation of genes encoding cellulolytic enzymes by Pal-PacC signaling in Aspergillus nidulans. Appl Microbiol Biotechnol. 2016;100:3621-35.

142. Lockington RA, Rodbourn L, Barnett S, Carter CJ, Kelly JM. Regulation by carbon and nitrogen sources of a family of cellulases in Aspergillus nidulans. Fungal Genet Biol. 2002;37:190-6.

\section{Submit your next manuscript to BioMed Central and we will help you at every step:}

- We accept pre-submission inquiries

- Our selector tool helps you to find the most relevant journal

- We provide round the clock customer support

- Convenient online submission

- Thorough peer review

- Inclusion in PubMed and all major indexing services

- Maximum visibility for your research

Submit your manuscript at www.biomedcentral.com/submit
Biomed Central 